\title{
Transcriptome profiling of Ricinus communis L. provides new insights underlying the mechanisms towards thermotolerance during seed imbibition and germination
}

\author{
Paulo R. Ribeiro ${ }^{\mathrm{a}, \mathrm{b}, \mathrm{c}, *}$, Leo A.J. Willems ${ }^{\mathrm{a}}$, Anderson T. Silva ${ }^{\mathrm{a}}$, Luzimar G. Fernandez ${ }^{\mathrm{c}}$, \\ Renato D. de Castro ${ }^{c}$, Johan Bucher ${ }^{\mathrm{d}}$, Basten L. Snoek ${ }^{\mathrm{e}, \mathrm{f}}$, Henk W.M. Hilhorst ${ }^{\mathrm{a}}$, Wilco Ligterink ${ }^{\mathrm{a}, * *}$ \\ ${ }^{a}$ Wageningen Seed Lab, Laboratory of Plant Physiology, Wageningen University, Droevendaalsesteeg 1, 6708 PB Wageningen, the Netherlands \\ ${ }^{\mathrm{b}}$ Metabolomics Research Group, Instituto de Química, Universidade Federal da Bahia, Rua Barão de Jeremoabo s/n, 40170-115, Salvador, Brazil \\ ${ }^{\mathrm{c}}$ Laboratório de Bioquímica, Biotecnologia e Bioprodutos, Departamento de Bioquímica, Universidade Federal da Bahia, Reitor Miguel Calmon s/n, 40160-100 Salvador, \\ Brazil \\ d Wageningen UR Plant Breeding, Wageningen, the Netherlands \\ e Laboratory of Nematology, Wageningen University, Droevendaalsesteeg 1, 6708 PB Wageningen, the Netherlands \\ ${ }^{\mathrm{f}}$ Theoretical Biology and Bioinformatics, Utrecht University, $3584 \mathrm{CH}$ Utrecht, the Netherlands
}

\section{A R T I C L E I N F O}

\section{Keywords:}

Cytochrome P450s

Heat shock proteins

Heat stress

Microarray analysis

Transcriptional regulation

\begin{abstract}
A B S T R A C T
Ricinus communis seeds germinate to a high percentage and faster at $35{ }^{\circ} \mathrm{C}$ than at lower temperatures, but with compromised seedling establishment and survival. However, seedlings are able to cope with high temperatures at later stages of seedling establishment if germination occurred at lower temperatures. The identification of this thermo-sensitive window during seed germination suggests that temperature disturb crucial mechanisms that support seedling establishment. We studied the molecular mechanisms that could explain this thermo-sensitive window with a genomics approach using microarray analysis to determine transcriptome changes during seed germination at 20,25 and $35^{\circ} \mathrm{C}$. Although temperature had a strong effect on the $R$. communis transcriptome, most of these differences occurred between $6 \mathrm{~h}$ of imbibition and the commencement of germination, i.e. radicle protrusion, which coincided with the identified thermo-sensitive window. We identified several responsive genes that might be involved in the thermotolerance of $R$. communis. Temperature had a major effect on genes involved in energy generating pathways, such as the Calvin-Benson-Bassham cycle, gluconeogenesis, and starch- and triacylglycerol degradation. Transcripts of ATP binding proteins, DNA binding proteins, RNA binding proteins, DNA-directed RNA polymerases, heat shock factor proteins, multiprotein-bridging factor proteins, and zinc finger proteins were also affected by temperature suggesting that transcriptional reprogramming mechanisms were disturbed. Among the downregulated transcripts, three were shared by all three stages: one oxidationrelated zinc finger 2, one F-box and wd40 domain protein, and one DNA binding protein/ MYB-like transcription factor. Among the upregulated transcripts, nine were shared by all three stages: one BET1P/SFT1P-like protein 14BB, one low-molecular-weight cysteine-rich protein LCR78, one WD-repeat protein, one GAST1 protein, one adenylate kinase 1/P-loop containing nucleoside triphosphate hydrolases superfamily protein, and four conserved hypothetical proteins. These genes constitute good candidate genes for further characterization of temperature-responsive molecular mechanisms in $R$. communis, which in turn will provide necessary tools for the exploitation of $R$. communis by small family farmers under the typical harsh conditions of semiarid regions worldwide.
\end{abstract}

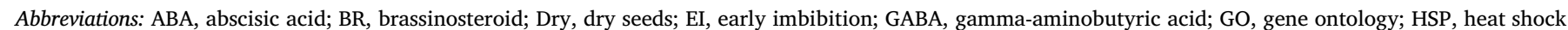

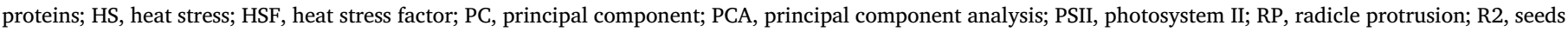
with a radicle of $2 \mathrm{~cm}$

* Corresponding author at: Metabolomics Research Group, Instituto de Química, Universidade Federal da Bahia, Rua Barão de Jeremoabo s/n, 40170-115, Salvador, Brazil.

** Corresponding author.

E-mail addresses: pauloribeiro@ufba.br, paulodc3@gmail.com (P.R. Ribeiro), wilcoligterink@gmail.com (W. Ligterink). 


\section{Introduction}

Temperature is one of the main environmental factors influencing seed germination and plant growth (Ribeiro et al., 2014, 2015a; Ribeiro et al., 2015b, d). Temperatures above the optimum are perceived as heat stress (HS) by all living organisms and this optimum temperature may vary between species (Chamorro et al., 2017; Cochrane, 2017). Heat stress damage consists of various sets of complex perturbations of the homeostasis of the plant, which depend on developmental stage, as well as types of plant tissues and organs (Akter and Rafiqul Islam, 2017; Fahad et al., 2017; Kotak et al., 2007). For example, heat stress may affects the stability of various proteins, membranes, RNA species and cytoskeleton structures, it alters the efficiency of enzymatic reactions thereby obstructing the major physiological processes, and creates metabolic imbalance (Akter and Rafiqul Islam, 2017; Fahad et al., 2017; Hasanuzzaman et al., 2013). In the course of evolution, plants have developed a variety of responses to elevated temperatures aiming at minimizing damage and ensuring protection of cellular homeostasis (Hasanuzzaman et al., 2013; Kotak et al., 2007; Wolfe and Tonsor, 2014). Some of the mechanisms to cope with high temperature involve changing leaf orientation, transpirational cooling, alteration of membrane composition, closure of stomata, increased stomatal and trichomatous densities, and larger xylem vessels (Hasanuzzaman et al., 2013; Wolfe and Tonsor, 2014; Zheng et al., 2011).

Transcriptome analysis of several plant species in response to temperature has revealed the involvement of heat stress responsive genes in the acquisition of thermo-tolerance (Li et al., 2013; Liao et al., 2015; Mangrauthia et al., 2016; Yan et al., 2016). For example, Liao et al. (2015) identify potential candidate genes involved in high night-temperature response in thermo-tolerant and -sensitive rice lines. Transcripts involved in electron transfer in the mitochondrial respiratory chain, mainly cytochrome P450 s, were found to be differentially expressed when comparing the heat-tolerant and -sensitive lines after high temperature exposure (Liao et al., 2015). Mitochondria play an important role in adjusting and maintaining cellular homeostasis. Therefore, disturbances in the electron transfer may prevent the proper functioning of mitochondria in response to different abiotic stresses, since the energy cost for biosynthetic processes cannot be fulfilled under these circumstances (Naydenov et al., 2010; Rachmilevitch et al., 2007). Spinach leaf de novo transcriptome analysis under heat stress showed that up to 1130 genes were up-regulated as compared to the control. Among the identified heat-responsive genes, transcription factors play an important role in response to early heat stress (Yan et al., 2016). Additionally, genes involved in salt stress, organic acid metabolic and carotenoid metabolic represented a special mechanism in spinach response to heat stress (Yan et al., 2016). Transcriptome analysis of Oryza sativa seed germination was assessed in an attempt to better understand gene expression and regulation during seed germination at high temperatures (Mangrauthia et al., 2016). The expression of genes involved in fatty acid, amino acid, carbohydrate, and energy metabolism were strongly affected by the temperature. Additionally, the results showed altered expression of transcripts associated with abscisic acid (ABA) and jasmonate signaling, antioxidants (peroxidase and ascorbate peroxidase), heat shock proteins (HSP 20 and HSP70 family), heat shock protein binding protein1 (HSPBP1, HSP70-interacting protein) and other stress associated pathways (Mangrauthia et al., 2016). Heat stress factors (HSFs) and Heat shock proteins (HSPs) play a central role in the response to heat stress and acquired thermotolerance in plants (Hasanuzzaman et al., 2013; Sun et al., 2002). Hsfs serve as the transcriptional activator component of signal transduction and mediate the expression of HSPs (Qu et al., 2013). Acquisition of thermotolerance through overexpression of HSF and HSP may be achieved by overexpression of single genes or a combination of genes (Kotak et al., 2007). For example, transgenic Arabidopsis plants overexpressing a wheat chloroplastic sHSP (HSP26) were substantially more tolerant to high temperature $\left(35^{\circ} \mathrm{C}\right)$ than wild-type plants, showing higher photosystem II (PSII) activity, higher biomass and seed yield. Additionally, the transgenic plants showed higher germination than the wild-type plants under high temperature $\left(35^{\circ} \mathrm{C}\right)$ (Chauhan et al., 2012).

The Brazilian National Program for Production and Use of Biodiesel has identified $R$. communis as the ideal oilseed crop to promote social development in the semi-arid region of Brazil because of its versatility as a productive (oil) crop in various environments (Cesar and Batalha, 2010). A thermo-sensitive window during $R$. communis seed germination in which high temperatures compromise seedling development has been previously identified (Ribeiro et al., 2015c). Nevertheless, there is a lack of information about the correlation between physiological events, such as germination and seedling establishment under high temperatures, and the associated transcriptome changes. Hence, we performed a functional genomics approach using microarray analysis to determine transcriptome changes during $R$. communis seed germination at 20,25 and $35^{\circ} \mathrm{C}$ that could explain its thermo-sensitive window.

\section{Materials and methods}

\subsection{Plant material and germination conditions}

Ricinus communis ( $c v$. MPB01) used in this study was developed by the breeding program of the Empresa Baiana de Desenvolvimento Agrícola S.A (EBDA-Brazil) (Santos et al., 2018). After seed coat removal, seeds were allowed to imbibe using wet paper at three different temperatures $\left(20,25\right.$ and $\left.35^{\circ} \mathrm{C}\right)$ in the dark. Four different stages were defined and sampled for follow-up experiments: dry seeds (Dry), early imbibition (EI), seeds at radicle protrusion (RP) and Kumar2 cm (R2) (Supplementary Figure S1). EI samples consisted of seeds that had imbibed for $6 \mathrm{~h}$ at $35^{\circ} \mathrm{C}$, for 7 at $25^{\circ} \mathrm{C}$, and for $8 \mathrm{~h}$ at $20^{\circ} \mathrm{C}$. Different lengths of imbibition were necessary in order to obtain a uniform seed water content of around $24 \%$ (Ribeiro et al., 2015b). All analyses were performed on three biological replicates of 20 seeds each.

\subsection{Microarray probe design}

The whole genome sequence of $R$. communis is publicly available (Chan et al., 2010). We designed microarray probes for the Agilent microarray platform based on the predicted gene models of the reference genome sequence v0.1 (as downloaded from Phytozome 10.0, http://phytozome.jgi.doe.gov/pz/portal.html\#! info?alias = Org

Rcommunis). From the $31,225 R$. communis predicted transcripts, 31,111 could be successfully used to design specific 60 -mer probes with the web based Agilent eArray tool (https://earray.chem.agilent.com/ earray/). The microarray layout (Design ID 058689) consists of 45,220 probes of which 1417 are standard Agilent control probes and 43,803 are $R$. communis specific probes corresponding to the 31,111 different $R$. communis transcript IDs.

\subsection{RNA extraction}

Total RNA was extracted according to the hot borate protocol modified by Wan and Wilkins (1994) and Gomes Neto et al. (2018). Approximately $20 \mathrm{mg}$ of ground seeds were mixed with $800 \mu \mathrm{l}$ of extraction buffer ( $0.2 \mathrm{M}$ Na borate decahydrate (Borax), $30 \mathrm{mM}$ EGTA, 1\% SDS, $1 \%$ Na deoxycholate (Na-DOC)) containing $1.6 \mathrm{mg}$ DTT and $48 \mathrm{mg}$ PVP40 which had been heated to $80^{\circ} \mathrm{C} .1 \mathrm{mg}$ proteinase $\mathrm{K}$ was added to this suspension and incubated for $15 \mathrm{~min}$ at $42^{\circ} \mathrm{C}$. After adding $64 \mu \mathrm{l}$ of $2 \mathrm{M}$ KCL the samples were incubated on ice for $30 \mathrm{~min}$ and subsequently centrifuged for $20 \mathrm{~min}$ at $12,000 \mathrm{~g}$. Ice-cold $8 \mathrm{M} \mathrm{LiCl}$ was added to the supernatant in a final concentration of $2 \mathrm{M}$ and the tubes were incubated overnight on ice. After centrifugation for $20 \mathrm{~min}$ at $12,000 \mathrm{~g}$ at $4^{\circ} \mathrm{C}$, the pellets were washed with $750 \mu \mathrm{l}$ ice-cold $2 \mathrm{M} \mathrm{LiCl}$. The samples were centrifuged for $10 \mathrm{~min}$ at $10,000 \mathrm{~g}$ at $4{ }^{\circ} \mathrm{C}$ and the pellets were resuspended in $100 \mu \mathrm{l}$ DEPC treated water. The samples were phenol chloroform extracted, DNAse treated according to the manufacturer's 
protocol (RQ1 DNase, Promega) and further purified with RNEasy spin columns (Qiagen) following the manufacturer's instructions. RNA quality and concentration were assessed by agarose gel electrophoresis and UV spectrophotometry.

\subsection{Experimental design for microarray hybridization}

Microarray hybridizations were performed as described by Basnet et al. (2013). Cy3 and Cy5 dyes were incorporated into cRNA samples according to the Agilent two-colour microarray based transcript expression analysis protocol (Low input quick Amp labelling G414090050, Agilent Technologies, Inc., Santa Clara, CA, USA) and hybridized on arrays following a specific design (Supplementary Figure S2).

\subsection{Microarray data analysis}

\subsubsection{Normalization}

Loess was used for within-array normalization and quantile normalization for between array normalization using the limma package in $\mathrm{R}$ (Basnet et al., 2013). The normalized Cy3 and Cy5 intensities were used as measures of transcript abundance. No background correction was performed as recommended by Zahurak et al. (2007). This approach has been successfully applied by Snoek et al. (2014). For further investigation $\log 2$ of the absolute intensities or the $\log 2$ ratio with the mean of each spot over all samples were used.

\subsubsection{ANOVA and multiple testing corrections}

ANOVA was used in a factorial design to find transcripts significantly affected by stage, temperature and the interaction between stage and temperature (FDR adjusted $\mathrm{p}<0.001$ ). We used a two-sided t-test, assuming unequal variance to determine if samples collected at $20^{\circ} \mathrm{C}$ and $35^{\circ} \mathrm{C}$ were significantly different within each stage. The obtained $\mathrm{p}$-values were adjust for multiple testing by the BY method in $\mathrm{R}$ (http://www.r-project.org/).

\subsubsection{Principal component analysis (PCA)}

Normalized data were uploaded in MetaboAnalyst 2.0; a web-based analytical pipeline for high-throughput studies as described previously (Bittencourt et al., 2015; Ribeiro et al., 2015a; Xia et al., 2012). Before data analysis, a data integrity check was performed to ensure that all the necessary information was present. Row-wise normalization was performed to allow general-purpose adjustment for differences among samples. Log transformation and auto-scaling were performed to allow comparison of features. Principal component analysis (PCA) was performed using log transformed and auto-scaled data.

\subsubsection{Venn diagram}

$R$. communis identifiers for each subset of differential expressed genes were used as input for the construction of the Venn diagram in the Venny 2.0 toolkit (http://bioinfogp.cnb.csic.es/tools/venny/).

\subsubsection{Singular enrichment analysis}

Finding enriched gene ontology (GO) terms corresponds to finding enriched biological facts, and the term enrichment level is judged by comparing the query list to a background population from which the query list is derived (Li et al., 2013). In this study, the background query list comprised of the 19,659 annotated $R$. communis transcripts (http://castorbean.jcvi.org/index.php). $R$. communis identifiers for each subset were used as input for singular enrichment analysis in the agriGO toolkit (http://bioinfo.cau.edu.cn/agriGO/index.php). The $R$. communis genome loci (TIGR) were selected as background. Fisher's statistical test and Yekutieli [false discovery rate (FDR) under dependency] for multi-test adjustment were selected to identify enriched GO categories with a significance level of 0.05 .

\section{Results and discussion}

\subsection{Genome wide variation in transcript levels during Ricinus communis} germination in response to temperature

\subsubsection{PCA analysis}

Initially, ANOVA was applied to the entire dataset aiming at finding significant changes in transcript levels in response to differences in developmental stage, temperature and interaction between developmental stage and temperature. Most of the observed changes in transcript levels were due to differences in developmental stage $(10,750$ transcripts), followed by temperature (500 transcripts) and the interaction between stage and temperature (304 transcripts) (Supplementary Table S1).

Principal component analysis (PCA) was performed for these three subsets of transcripts, individually (Fig. 1). For the subset of transcripts significantly affected by developmental stage, principal component 1 (PC1) explained $69.7 \%$ of the total variance, whereas principal component 2 (PC2) explained 9.6\% (Fig. 1a). PC1 effectively separated dry and EI seeds from RP and R2 seeds. PC2 mainly separated the a)

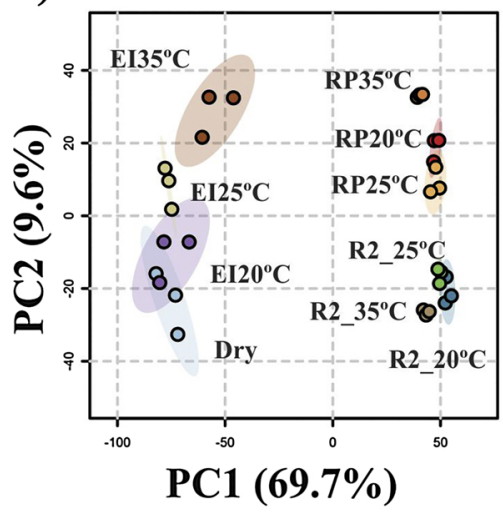

b)

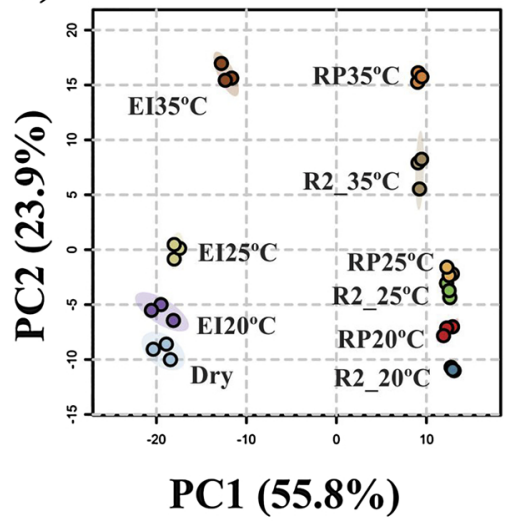

c)

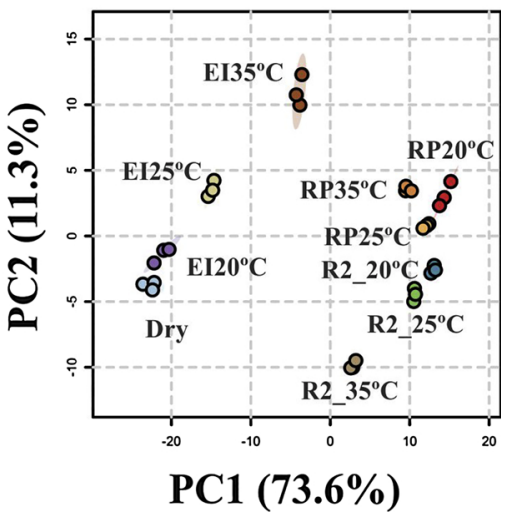

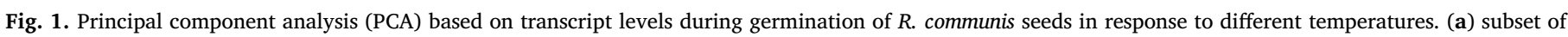

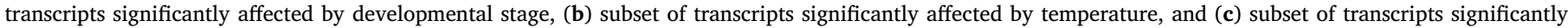

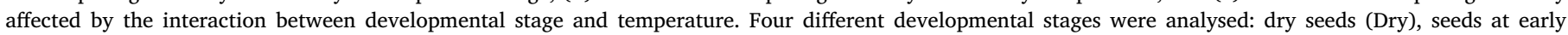

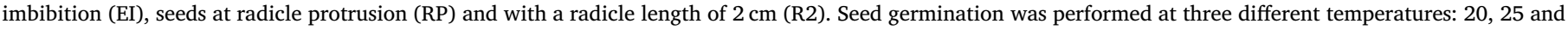
$35^{\circ} \mathrm{C}$. 
contribution of temperature, although it also distinguished RP seeds from R2 seeds. For the subset of transcripts significantly affected by temperature, PC1 explained $55.8 \%$ of the total variance, whereas PC2 explained $23.9 \%$ (Fig. 1b). Again, PC1 effectively discriminated dry and EI seeds from RP and R2 seeds, whereas PC2 reflected the contribution of temperature. For the subset of transcripts significantly affected by the interaction between developmental stage and temperature, PC1 explained $73.6 \%$ of the total variance, whereas PC2 explained $11.3 \%$ (Fig. 1c). Although, it seems that PC1 played the major role in separating dry and EI seeds from RP and R2 seeds, PC2 also contributed to this separation. Similarly, PC1 and PC2 seem to act together to separate the contribution of temperature. It is worth to highlight that regardless of the stage, seeds imbibed at $35^{\circ} \mathrm{C}$ were clearly differing from seeds imbibed at $20^{\circ} \mathrm{C}$ and $25^{\circ} \mathrm{C}$. Therefore, using the concept that proximity means similarity, seeds that had imbibed at $20^{\circ} \mathrm{C}$ and $25^{\circ} \mathrm{C}$ seem to be closer related in terms of transcriptome, than seeds imbibed at $35^{\circ} \mathrm{C}$. Principal component analysis applied to the overall variation in metabolite composition of $R$. communis seeds that germinated at $20^{\circ} \mathrm{C}, 25^{\circ} \mathrm{C}$ and $35{ }^{\circ} \mathrm{C}$ indicated that most of the variation was attributed to differences in the developmental stage rather than to temperature (Ribeiro et al., 2015c). Therefore, transcriptome profiling provides additional and broader possibilities to identify the mechanisms underlying Ricinus communis thermotolerance during seed imbibition and germination.

\subsubsection{Singular enrichment analysis}

To investigate the biological significance of the transcripts within a given subset it is enlightening to identify the gene ontologies (GO) associated with these transcripts. Therefore, we identified enriched GO terms associated with each subset of transcripts. GO terms are divided in three groups: biological processes, molecular functions, and cellular components. In this study, we focused our attention mainly on GO terms related to biological processes and molecular functions. Additionally, because the main objective of this study is to unravel the changes in the transcriptome in response to temperature, we decided to selected only two subsets for singular enrichment analysis. These subsets consisted of transcripts significantly affected by temperature (ST) and by the interaction between developmental stage and temperature (SST).

For the transcripts belonging to ST, only one GO term associated with biological processes was enriched: metabolic processes (133 out of 262 transcripts) (Fig. 2a). Transcripts in the GO metabolic processes are associated with important energy generating pathways, such as the Calvin-Benson-Bassham cycle, gluconeogenesis, starch degradation, and triacylglycerol degradation. For example, transcript levels of sedoheptulose-1,7-bisphosphatase (29610.m000407) were up to 5.3-fold higher in RP and R2 imbibed at $20^{\circ} \mathrm{C}$ and $25^{\circ} \mathrm{C}$ than at $35^{\circ} \mathrm{C}$ (Supplementary Table S1). This gene is a major regulatory step in the control of the Calvin cycle. The Calvin cycle is a metabolic pathway responsible for the fixation of carbon and it is located in the stroma of the chloroplasts. Carbon enters this cycle as $\mathrm{CO}_{2}$, which is then used in the carboxylation of ribulose-1,5-bisphosphate to produce 3-phosphoglycerate by the enzyme ribulose-1,5-bisphosphate carboxylase/oxygenase (RuBisCO). For every three molecules of $\mathrm{CO}_{2}$ that enter the cycle, the net output is one molecule of 3-phosphoglycerate (3PGA) (Raines,

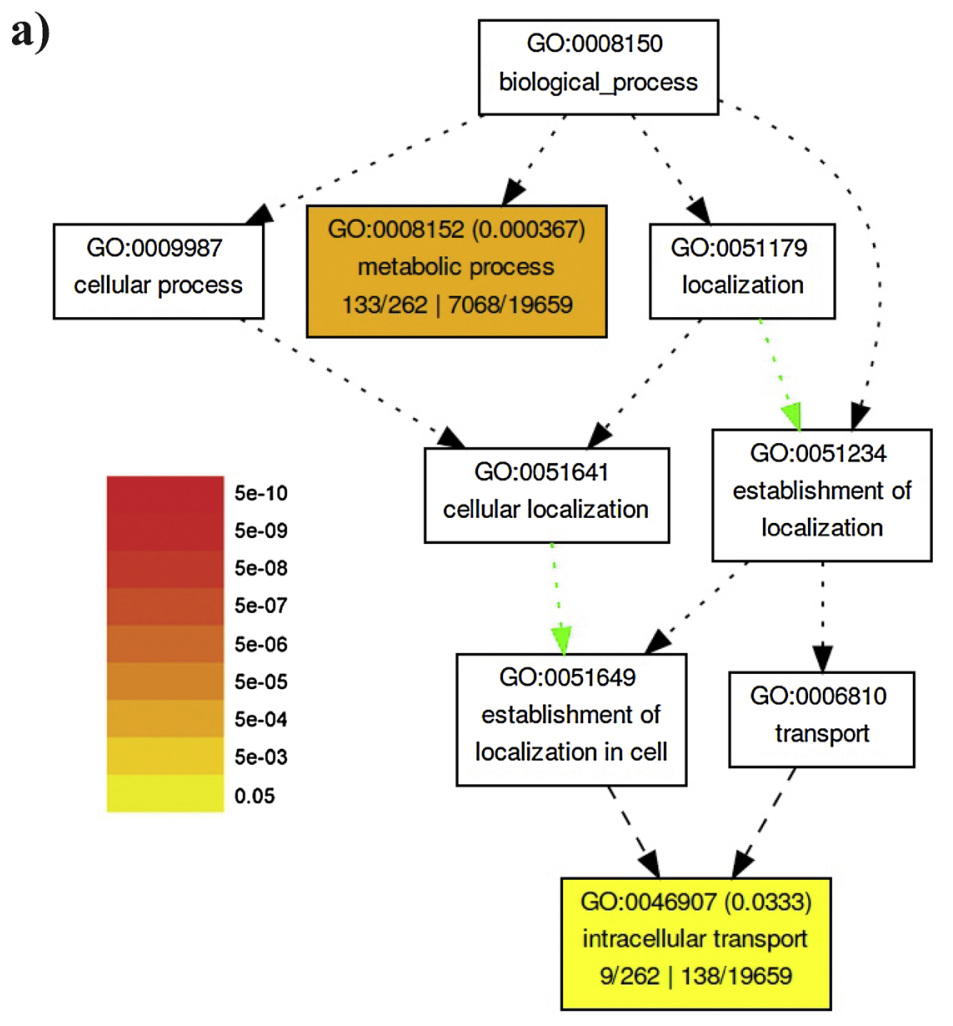

b)

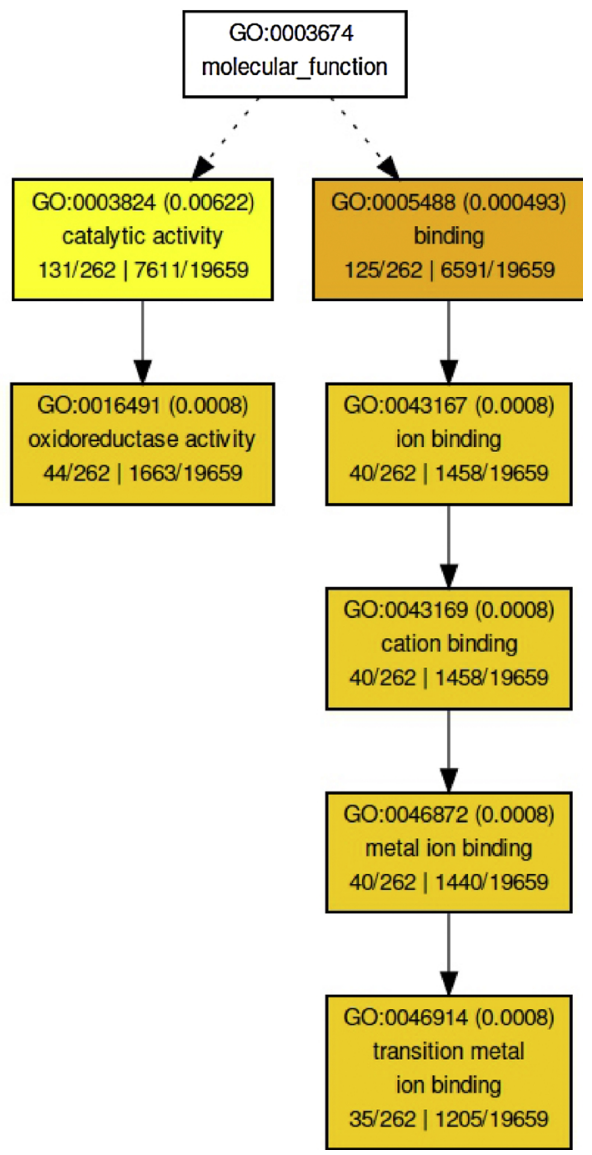

Fig. 2. Gene ontology analysis of transcripts significantly affected by temperature in R. communis using agriGO. (a) Significantly over-represented GOs associated with biological processes and (b) Significantly over-represented GOs associated with molecular function. Boxes in the graph represent GO terms labeled by their GO ID, term definition and statistical information. The significant term (adjusted $\mathrm{P} \leq 0.05$ ) are marked with color, while non-significant terms are shown as white boxes. The diagram, the degree of color saturation of a box is positively correlated to the enrichment level of the term. Solid, dashed, and dotted lines represent two, one and zero enriched terms at both ends connected by the line, respectively. 
2003). Then, 3PGA can be converted into three forms of hexose phosphate (glucose 1-phosphate, glucose 6-phosphate, and fructose 6phosphate) in a pathway parallel to that of gluconeogenesis (Berg et al., 2002). Another important pathway present in this GO term is starch degradation. Transcript levels of a $\beta$-amylase (29726.m003986) were up to 3.7-fold higher in RP and R2 imbibed at $20^{\circ} \mathrm{C}$ and $25^{\circ} \mathrm{C}$ than at $35^{\circ} \mathrm{C}$ (Supplementary Table S1). Starch degradation in the endosperm is assumed to differ from that in other organs (Smith et al., 2005). Nevertheless, starch degradation is accompanied by increases in carbohydrates such as maltose and sucrose, but also provides carbon skeletons and energy (Smith et al., 2005). Finally, transcripts involved in triacylglycerol degradation were also present in the GO term metabolic processes. For example, the transcript 29864.m001449 showed high homology to a GDSL-motif lipase 5 in Arabidopsis. Levels of this transcript were up to 3.5 -fold higher in RP and R2 imbibed at $20^{\circ} \mathrm{C}$ and $25^{\circ} \mathrm{C}$ than at $35^{\circ} \mathrm{C}$ (Supplementary Table S1). Triacylglycerol degradation starts with the onset of seed germination and occurs in the glyoxysomes. All these pathways have one thing in common: production of compounds that are converted to soluble sugars which are used presumably to fuel seedling growth (Berg et al., 2002; Graham, 2008; Raines, 2003; Smith et al., 2005). Therefore, it is safe to assume that temperature has a major role in metabolic processes, which are crucial to support successful seedling establishment.

Continuing with the analysis of transcripts belonging to ST, we found that two GO terms associated with molecular functions were enriched: catalytic activity (131 out of 262 transcripts) and binding (125 out of 262 transcripts). Under the GO category of catalytic activity, only the GO term oxidoreductase activity was enriched, whereas under the GO category of binding, four GO terms related with ion binding were enriched (Fig. 2b). Transcripts within GO term oxidoreductase activity included several alcohol- and aldehyde dehydrogenases and cytochrome P450 s. Cytochrome P450 s are a large and ubiquitously distributed group of heme-containing monooxygenases which catalyze a broad myriad of reactions such as carbon hydroxylation, heteroatom oxygenation, dealkylation, epoxidation, aromatic hydroxylation, reduction, and dehalogenation (Harris et al., 2018; Hausjell et al., 2018; Wei et al., 2018). In particular, cytochrome P450 s are involved in the biosynthesis of plant secondary metabolites and hormones, and play important roles in the regulation of plant growth and development (Hausjell et al., 2018). To illustrate the potential contribution of $R c P 450$ to explain faster germination at $35^{\circ} \mathrm{C}$ than at lower temperatures, we focused on two RcP450 present in the subset ST: RcP450a (29982.m000224) and RcP450b (30174.m009066).

Levels of RcP450a were higher in EI and RP imbibed at $35^{\circ} \mathrm{C}$ than at $20^{\circ} \mathrm{C}$ and $25^{\circ} \mathrm{C}$. In R2, levels of RcP450a showed little variation in response to temperature (Fig. 3a). RcP450a showed high homology to four CYP707A-like cytochrome P450s in Arabidopsis: CYP707A1 (AT4G19230), CYP707A2 (AT2G29090), CYP707A3 (AT5G45340), and CYP707A4 (AT3G19270). Cytochrome P450 CYP707As encode key enzymes in abscisic acid (ABA) catabolism: ABA 8'-hydroxylases (Kushiro et al., 2004; Wang et al., 2016; Zhenzhen et al., 2018). ABA 8 -hydroxylase catalyzes the conversion of $\mathrm{ABA}$ to $8^{\prime}$-hydroxy-ABA (Fig. 3b). Expression analysis revealed that Arabidopsis CYP707A2 is responsible for the rapid decrease in ABA level during seed imbibition (Kushiro et al., 2004). Levels of transcripts involved in ABA catabolism are higher in WT Arabidopsis seeds imbibing at $32{ }^{\circ} \mathrm{C}$ than at $21^{\circ} \mathrm{C}$ (Chiu et al., 2012). Since ABA is known to inhibit seed germination (Goggin et al., 2009), we raise the hypothesis that faster germination of $R$. communis seeds at higher temperatures might be regulated by the catabolic inactivation of ABA via hydroxylation at its $8^{\prime}$ position to form $8^{\prime}$-hydroxy-ABA as a means of further regulating ABA concentrations.

In contrast, levels of $R c P 450 b$ were higher in R2 seeds imbibed at $20^{\circ} \mathrm{C}$ and $25^{\circ} \mathrm{C}$ than at $35^{\circ} \mathrm{C}$. In EI, levels of RcP450b showed little variation in response to temperature (Fig. 3c). RcP450b showed high homology to cytochrome P450 CYP734A1 in Arabidopsis. CYP734A1 encodes a member of the cytochrome P450 family that serves as a control point between multiple photoreceptor systems and brassinosteroid (BR) signal transduction (Que et al., 2017; Sandhu et al., 2012). CYP734A1 also inactivates castasterone and brassinolide by means of C26 hydroxylation (Fig. 3d) (Que et al., 2017; Sandhu et al., 2012). Brassinosteroid (BR) are steroid hormones which regulate plant development, physiology, and responses to biotic and abiotic stresses (Hou et al., 2017; Lv et al., 2018; Unterholzner et al., 2015; Wang et al., 2013). Studies on mutants with defects in BR biosynthesis or signaling a) CYP707A-like cytochrome P450 29982. m000224

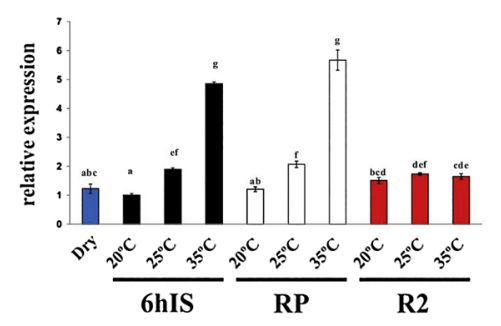

c)

$$
\text { CYP72B1-like cytochrome P450 }
$$
30174.m009066

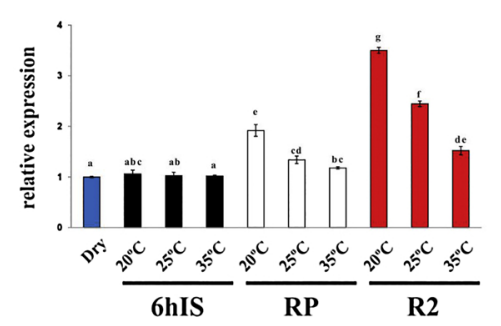

b)

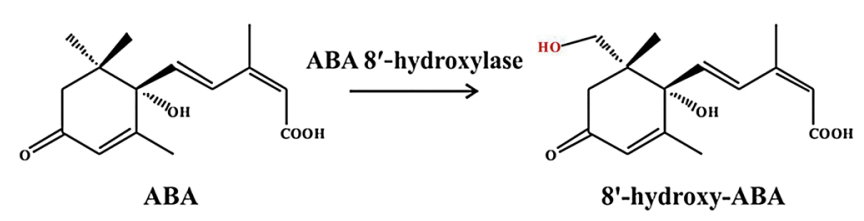

d)

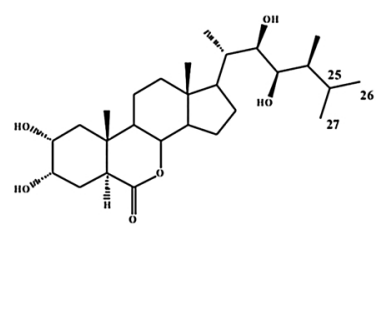

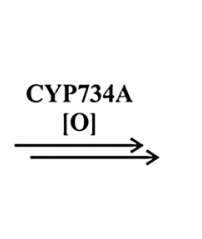

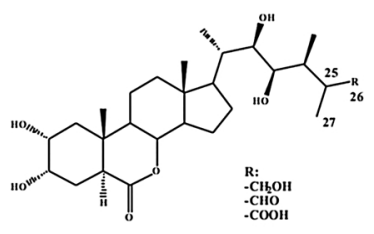

Fig. 3. (a) Transcript levels of RcP450a during germination of $R$. communis seeds in response to different temperatures, (b) conversion of ABA to 8 '-hydroxy-ABA by ABA 8'-hydroxylase, (c) Transcript levels of RcP450b during germination of $R$. communis seeds in response to different temperatures, (d) C-26 hydroxylation of castasterone and brassinolide by CYP734 A. Means and standard errors of three biological replicates containing 15-20 seeds each are shown. Temperatures are depicted in the graphs. Different letters above the bars indicate significant differences between samples by Tukey's HSD (p < 0.05). 
demonstrated that BR plays essential roles in nearly all phases of plant development, as these mutants show multiple developmental defects, such as reduced seed germination, extreme dwarfism, photomorphogenesis in the dark, altered distribution of stomata, delayed flowering and male sterility (Gomes, 2011; Hou et al., 2017; Jiang et al., 2013; Lv et al., 2018; Unterholzner et al., 2015; Wang et al., 2013). Brassinosteroids stimulate seed germination and BR signaling is required to overcome inhibition of germination by $\mathrm{ABA}$ (Steber and McCourt, 2001). Higher levels of $R c P 450 b$ in seeds imbibing at $20^{\circ} \mathrm{C}$ could explain the slower germination of $R$. communis seeds at lower temperatures.
Transcripts within GO term binding encompassed several ATP binding proteins, DNA binding proteins, RNA binding proteins, such as splicing factors, ccaat-binding transcription factor subunit A, chaperones, DNA-directed RNA polymerases I, II, and III, heat shock factor proteins, multiprotein-bridging factor proteins, and zinc finger protein. The DNA binding protein ID 29883.m001955 showed high homology with $A$. thaliana heat shock transcription factor A6B (AT3G22830). In general, plants have a flexible and specialized network of heat shock factors (HSFs), which induce the expression of heat shock proteins (Soares-Cavalcanti et al., 2012). The RNA binding protein ID 29709.m001182 showed high homology with an A. thaliana RNA-

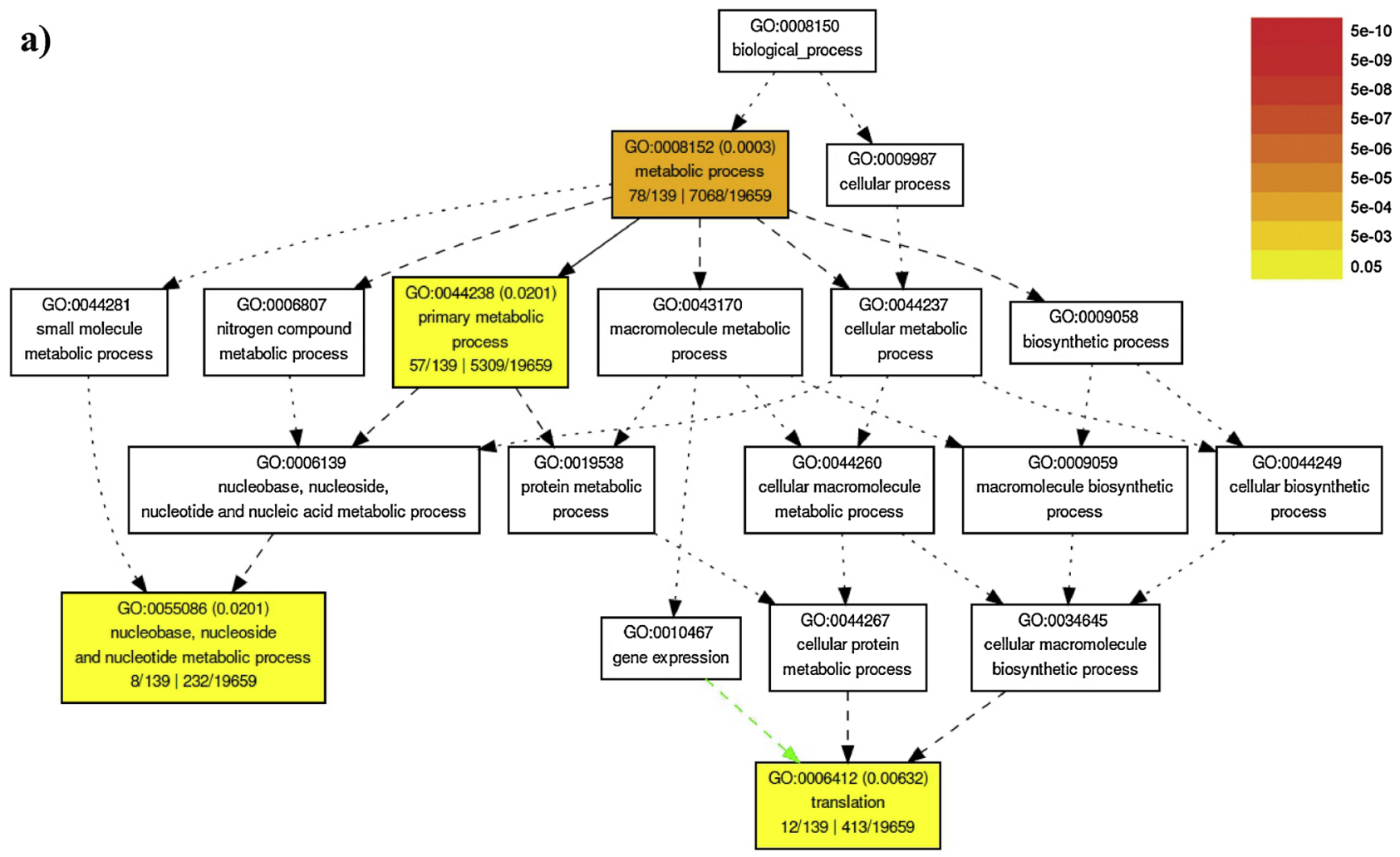

b)

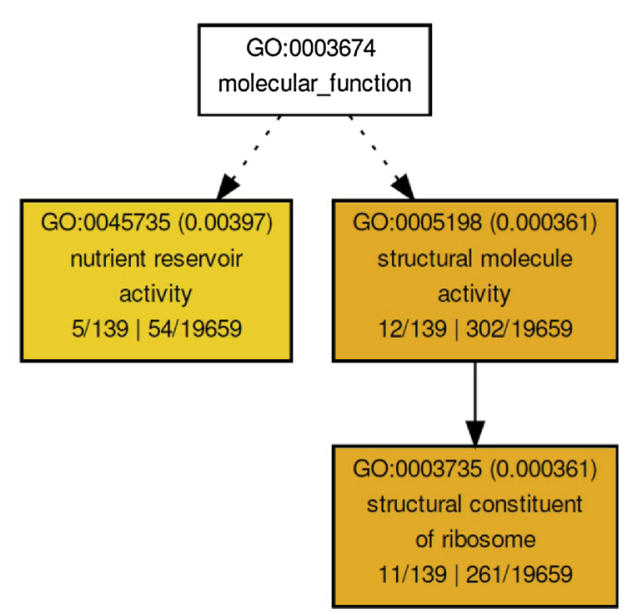

Fig. 4. Gene ontology analysis of transcripts significantly affected by the interaction between developmental stage and temperature in R. communis using agriGO. (a) Significantly over-represented GO terms associated with biological processes and (b) Significantly over-represented GO terms associated with molecular function. Boxes in the graph represent GO terms labeled by their GO ID, term definition and statistical information. The significant term (adjusted P $\leq 0.05$ ) are marked with color, while non-significant terms are shown as white boxes. The diagram, the degree of color saturation of a box is positively correlated to the enrichment level of the term. Solid, dashed, and dotted lines represent two, one and zero enriched terms at both ends connected by the line, respectively. 
nutrient reservoir 29709.m001187

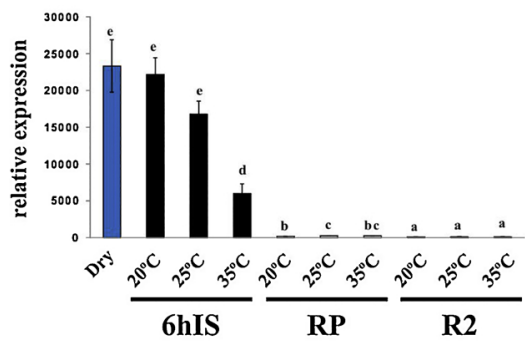

legumin 29200.m000167

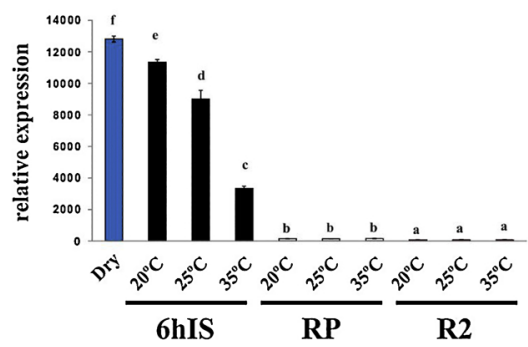

$11 \mathrm{~S}$ globulin

29629.m001355

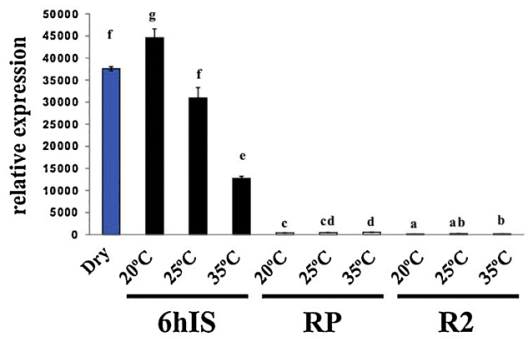

legumin

29600.m000561 glutelin

29200.m000169

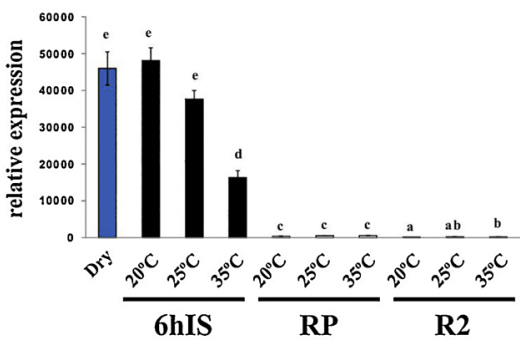

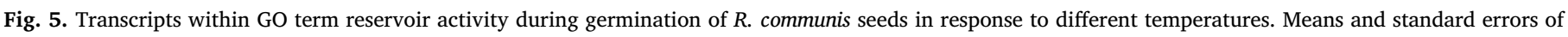

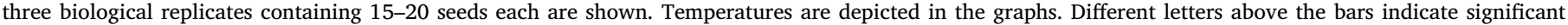
differences between samples by Tukey's HSD ( $p<0.05$ ).

binding (RRM/RBD/RNP motifs) family protein (AT2G44710). These proteins are conserved in plants and play important roles in normal plant growth and development (Peal et al., 2011). DNA-directed RNA polymerases are responsible for the polymerization of ribonucleotides into a sequence complementary to the template DNA. Most RNA polymerases are multimeric enzymes and are composed of a variable number of subunits (Horgen and Key, 1973). Taken together, the set of genes within this GO class indicates that temperature has a large effect on transcriptional reprogramming during germination of R. communis seeds.

For the transcripts belonging to SST, also only one GO term associated with biological processes was enriched: metabolic processes (78 out of 139 transcripts) (Fig. 4a). Under the GO category of metabolic processes, primary metabolic process (57 out of 139 transcripts) was enriched in response to temperature. Transcripts in this GO are associated with glycolysis IV (plant cytosol), starch biosynthesis, trehalose biosynthesis I, and UDP-glucose biosynthesis (from sucrose). We argued that most transcripts belonging to ST are involved in the production of compounds that are converted to soluble sugars. Not surprisingly, transcripts belonging to SST are involved in pathways that aim at obtaining energy from carbohydrates, such as glycolysis. Hence, these results support our previous statement that temperature plays a major role in metabolic processes that are crucial to support successful seedling establishment.

Two GO terms associated with molecular functions were enriched in the SST set: nutrient reservoir activity (5 out of 139 transcripts) and structural molecule activity (12 out of 139 transcripts) (Fig. 4b). Transcripts within GO class reservoir activity encompassed mainly globulins. Globulins are prevalent seed storage proteins of dicotyledonous flowering plants (Borroto and Dure Iii, 1987). In R. communis, the subunit polypeptides of the $11 \mathrm{~S}$ globulin are synthesized as high molecular weight precursors with heterogeneous molecular weights (Fukasawa et al., 1988). The 11S globulin gene family has been characterized in $R$. communis (Chileh et al., 2010; Li et al., 2012). Their expression profile indicates that they are seed specific and developmentally regulated, with a maximum expression when endosperm reaches its full expansion (Chileh et al., 2010). During imbibition of $R$. communis seeds, the levels of these transcripts decreased with increasing temperature (Fig. 5). As the germination proceeds, these globulins are responsible for the release of auxin. Auxin is an important plant hormone mediating cell division and elongation, root and shoot differentiation, development of the vascular system, and flowering in plants. In addition, this hormone acts as a messenger for abiotic and biotic stimuli (Kumar et al., 2017). Under the GO category of structural molecule activity, structural constituent of ribosome (11 out of 139 transcripts) was enriched in response to temperature (Fig. 4b). Transcripts within this GO encompass $40 \mathrm{~S}, 50 \mathrm{~S}$, and $60 \mathrm{~S}$ ribosomal proteins. Transcripts encoding ribosomal proteins are required for new ribosome formation during seed germination, when most of the metabolic machinery is re-activated (Jiménez-López et al., 2011).

\subsection{Stage-specific variation in transcript levels in response to temperature}

\subsubsection{PCA analysis}

In the next step, we analyzed the differential expression of transcripts for each individual stage in response to temperature using a twosided t-test, assuming unequal variance. We compared samples collected at $20^{\circ} \mathrm{C}$ and $35^{\circ} \mathrm{C}$ within each individual stage. This resulted in 365 transcripts differentially expressed in response to temperature at EI, 2010 transcripts at RP, and 975 transcripts at R2, indicating temperature has a large effect on transcriptional reprogramming at later stages of germination.

Principal component analysis (PCA) was performed individually for these three subset of transcripts (Supplementary Fig. 3). For the subset of transcripts selected for EI seeds, principal component 1 (PC1) explained $66.3 \%$ of the total variance, whereas principal component 2 (PC2) explained $16.2 \%$ (Supplementary Fig. 3a). PC1 effectively separated dry and EI seeds from RP and R2 seeds. PC2 mainly discriminated the contribution of temperature. It is worth to highlight that PC2 is responsible for the great separation of EI seeds. This highlights the robustness of the analysis in discriminating the effect of temperature on EI seeds as compared with RP and R2 seeds. For the subset of transcripts 


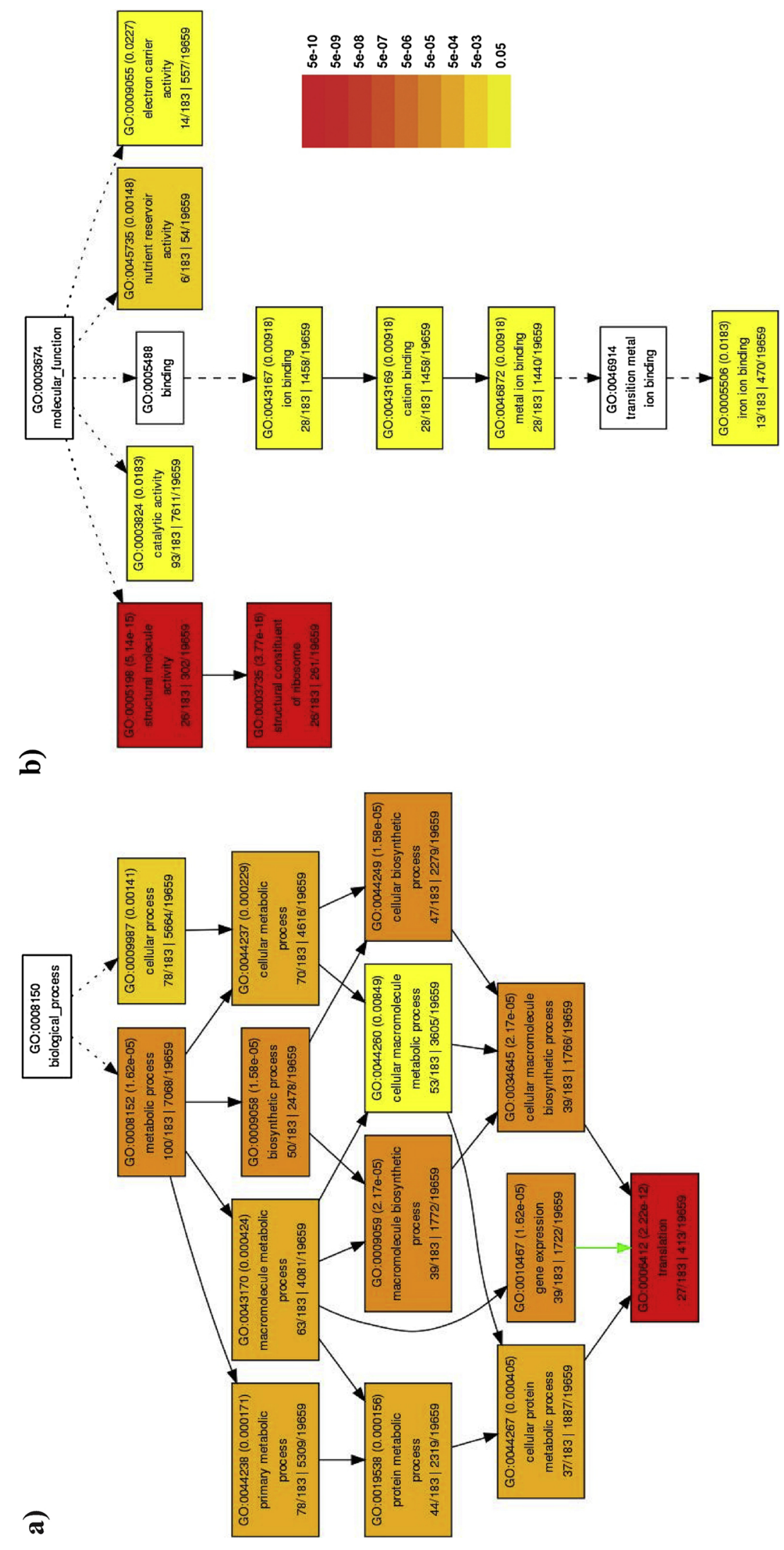

Fig. 6. Gene ontology analysis of the subset of transcripts differentially expressed in EI seeds using agriGO. (a) Significantly over-represented GO terms associated with biological processes and (b) Significantly over-represented GO terms associated with molecular function. Boxes in the graph represent GO terms labeled by their GO ID, term definition and statistical information. The significant term (adjusted $P \leq 0.05)$ are marked with color, while non-significant terms are shown as white boxes. The diagram, the degree of color saturation of a box is positively correlated to the enrichment level of the term. Solid, dashed, and dotted lines represent two, one and zero enriched terms at both ends connected by the line, respectively.

selected for RP seeds, PC1 explained $56.0 \%$ of the total variance, whereas PC2 explained 13.4\% (Supplementary Fig. 3b). Again, PC1 effectively separated dry and EI seeds from RP and R2 seeds. Although $\mathrm{RP}$ seeds imbibed at $35^{\circ} \mathrm{C}$ were clearly differing from RP and R2 seeds imbibed at $20^{\circ} \mathrm{C}$ and $25^{\circ} \mathrm{C}$, no clear separation between RP seeds imbibed at $20^{\circ} \mathrm{C}$ and $25^{\circ} \mathrm{C}$ was observed. For the subset of transcripts selected for R2 seeds, PC1 explained $59.3 \%$ of the total variance, whereas PC2 explained 13.6\% (Supplementary Fig. 3c). PC1 separated 


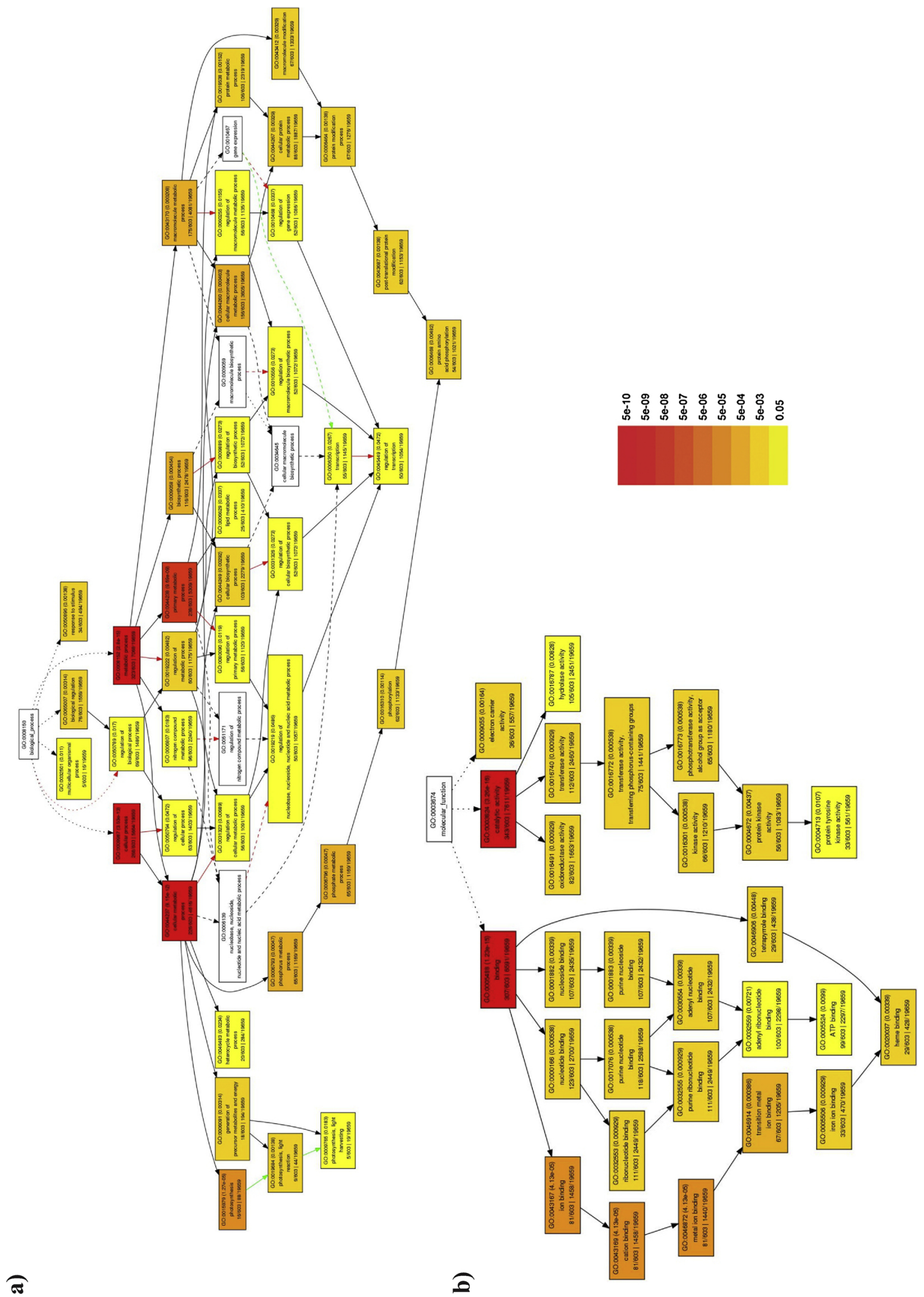

Fig. 7. Gene ontology analysis of the down-regulated genes of the subset of transcripts differentially expressed in RP seeds using agriGO. (a) Significantly overrepresented GO terms associated with biological processes and (b) Significantly over-represented GO terms associated with molecular function. Boxes in the graph represent GO terms labeled by their GO ID, term definition and statistical information. The significant term (adjusted P $\leq 0.05$ ) are marked with color, while nonsignificant terms are shown as white boxes. The diagram, the degree of color saturation of a box is positively correlated to the enrichment level of the term. Solid, dashed, and dotted lines represent two, one and zero enriched terms at both ends connected by the line, respectively. 

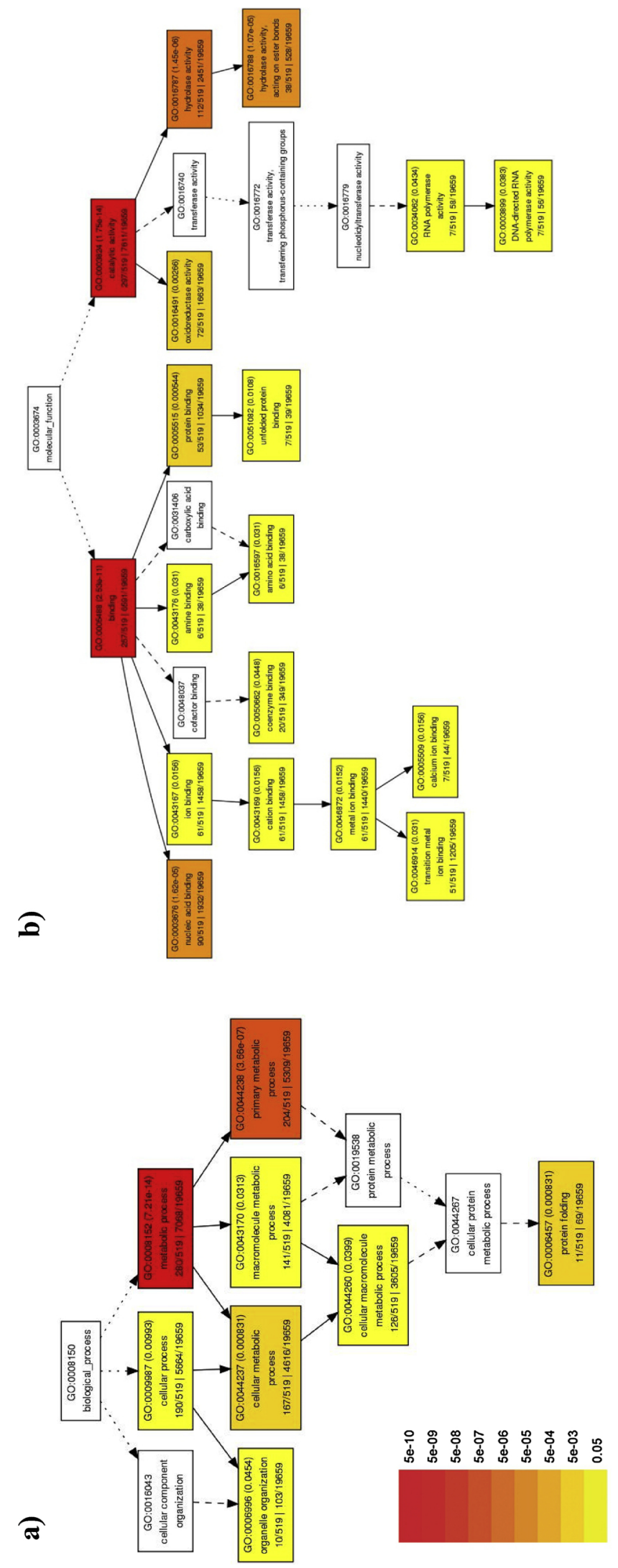

Fig. 8. Gene ontology analysis of the upregulated genes of the subset of transcripts differentially expressed in RP seeds using agriGO. (a) Significantly overrepresented GO terms associated with biological processes and (b) Significantly over-represented GO terms associated with molecular function. Boxes in the graph represent GO terms labeled by their GO ID, term definition and statistical information. The significant term (adjusted $\mathrm{P} \leq 0.05$ ) are marked with color, while non-significant terms are shown as white boxes. The diagram, the degree of color saturation of a box is positively correlated to the enrichment level of the term. Solid, dashed, and dotted lines represent two, one and zero enriched terms at both ends connected by the line, respectively.

dry and EI seeds from RP and R2 seeds, whereas PC2 discriminated the contribution of temperature. An overlap was observed among dry seeds and EI seeds imbibed at $20^{\circ} \mathrm{C}$ and $25^{\circ} \mathrm{C}$. EI seeds imbibed at $35^{\circ} \mathrm{C}$ were, however, clearly differentiated from EI seeds imbibed at $20^{\circ} \mathrm{C}$ and $25^{\circ} \mathrm{C}$. Taken together, the closeness of RP and R2 seeds appears to be more related to temperature than to developmental stage.

\subsubsection{Singular enrichment analysis}

For transcripts differential expressed in EI, two GO terms associated with biological processes were enriched: metabolic processes (100 out of 183 transcripts) and cellular processes (78 out of 183 transcripts) (Fig. 6a). Transcripts in these GOs are associated with gluconeogenesis I, $\beta$-oxidation, Calvin-Benson-Bassham cycle, fatty acid activation, starch degradation II, and tRNA charging. Four GO terms associated with molecular functions were enriched: structural molecule activity (26 out of 183 transcripts), catalytic activity (93 out of 183 transcripts), nutrient reservoir activity ( 6 out of 183 transcripts) and electron carrier activity (14 out of 183 transcripts) (Fig. 6b). Transcripts within GO electron carrier activity include mainly cytochrome P450 proteins. These results show that the effect of temperature on major energygenerating metabolic processes is initiated very early during imbibition. Nonetheless, in order to obtain further insights to explain the compromised seedling establishment of $R$. communis at high temperatures, we decided to focus on the metabolic changes that occurred at the RP stage. The main reason to focus on the RP stage is because we have identified a temperature sensitive window during germination, i.e. before radicle protrusion, in which high temperatures compromise seedling development (Ribeiro et al., 2015c).

We started our analysis with down-regulated transcripts differential expressed at RP with increasing temperatures. For this subset, several GO terms associated with biological processes were enriched such as multicellular organismal process (5 out of 603 transcripts), cellular process (268 out of 603 transcripts), biological regulation (76 out of 603 transcripts), metabolic process (323 out of 603 transcripts), and response to stimulus (34 out of 603 transcripts) (Fig. 7a). Transcripts within GO class multicellular organismal process include two serinethreonine protein kinases. Transcripts within GO class cellular process include several ATP binding proteins, serine-threonine protein kinases, a receptor protein kinase, a calcium-dependent protein kinase, WRKY transcription factors, and several transcripts of the hydrogen production VIII pathway, pentose phosphate pathway (oxidative branch), glycolysis IV (plant cytosol), RuBisCO shunt, and UDP-glucose biosynthesis. Transcripts within the GO class metabolic process include transcripts involved in abscisic acid biosynthesis, the Calvin-BensonBassham cycle, hydrogen production VIII, the pentose phosphate pathway (oxidative branch), and starch biosynthesis. For the downregulated transcripts belonging to RP, three GO terms associated with molecular function were enriched: binding (307 out of 603 transcripts), catalytic activity (343 out of 603 transcripts), and electron carrier activity (36 out of 603 transcripts) (Fig. 7b). Thus, based on these results it appears that high temperature compromises seedling development by 
a)

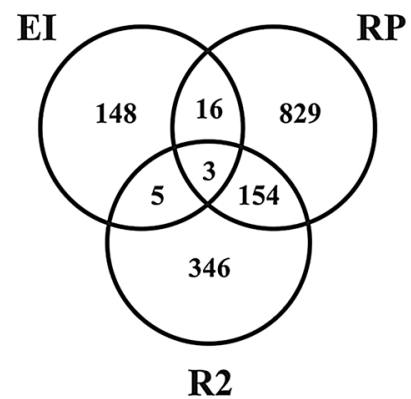

b)

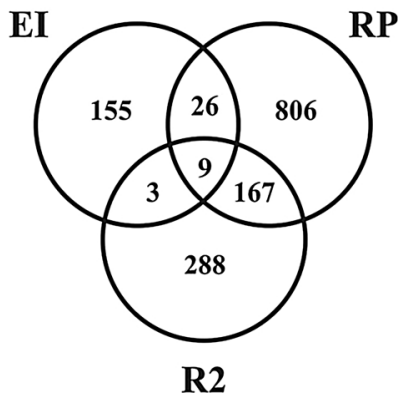

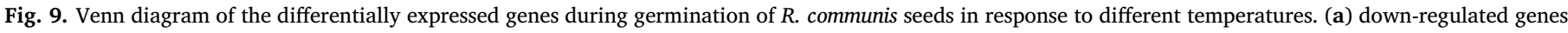
and (b) upregulated genes.

down-regulating metabolic processes which are crucial to support successful seedling establishment.

We also looked at the upregulated transcripts belonging to RP, two GO terms associated with biological processes were enriched: cellular processes (190 out of 519 transcripts), and metabolic processes (390 out of 519 transcripts) (Fig. 8a). Transcripts within GO cellular processes include chaperones, DNA-directed RNA polymerases, heat shock factor proteins, heat shock proteins, a receptor serine/threonine kinase, and receptor protein kinase CLAVATA1. Transcripts within GO term metabolic processes include transcripts involved in fatty acid activation, pyridoxal 5'-phosphate salvage II (plants) and triacylglycerol degradation (Fig. 8b).

Heat stress can cause serious deleterious effects in plants, such as disturbance of cellular homeostasis and destabilization of proteins, membranes, and RNA species, which can lead to severe retardation in growth and development, and even death (Hasanuzzaman et al., 2013; Kotak et al., 2007; Qu et al., 2013). We have demonstrated that seeds, which germinated at high temperature, reprogrammed their transcriptome and metabolome profiles in order to counterbalance the effect of high temperature. At the transcriptome level, this reprogramming involved the activation of protection mechanisms, mainly through upregulation of transcripts encoding for heat shock proteins and heat shock factor proteins. Heat shock proteins play an important role in protein folding and conformation, stabilizing partially unfolded proteins and preventing undesirable protein aggregation (Lee and Vierling, 2000). Therefore, the enrichment of the GO terms associated with chaperones, DNA-directed RNA polymerases, heat shock factor proteins and heat shock proteins is not surprising, since a large number of proteins can be misfolded under heat stress. Most importantly, these results support the fact that $R$. communis seeds perceive $35^{\circ} \mathrm{C}$ as a stress condition (Ribeiro et al., 2015c, d).

\subsubsection{Mining for similar responses in regulation of gene expression to temperature}

In order to find temperature-responsive genes shared by all three stages, we produced a Venn diagram with genes down- and upregulated at EI, RP, and R2 (Fig. 9). Regardless of the subset analyzed (transcripts down- or upregulated), RP and R2 shared more transcripts between them than with EI. For example, among the down-regulated RP and R2 shared 154 transcripts, whereas RP shared 16 transcripts with EI. R2 shared even less similarities with EI with only five transcripts. Among the upregulated transcripts, RP and R2 shared 164, whereas RP shared 26 transcripts with EI and R2 shared only three transcripts with EI. Thus, although temperature has a strong effect on the $R$. communis transcriptome, most of these differences occurred between $6 \mathrm{~h}$ of imbibition and the commence of germination, i.e. radicle protrusion. This coincides with the thermo-sensitive window identified during seed germination in which high temperatures compromise seedling development (Ribeiro et al., 2015c).

Only three transcripts were down-regulated at all three stages: one oxidation-related zinc finger 2 (29794.m003367), one F-box and wd40 domain protein (29929.m004787), and one DNA binding protein/ MYB-like transcription factor (29805.m001497) (Fig. 9a). Among the upregulated transcripts, nine were shared by all three stages: one BET1P/SFT1P-like protein 14BB (29603.m000532), one low-molecularweight cysteine-rich protein LCR78 (27436.m000276), one WD-repeat protein (27436.m000276), one GAST1 protein (30170.m013769), one adenylate kinase 1/P-loop containing nucleoside triphosphate hydrolases superfamily protein (30190.m010959), and four conserved hypothetical proteins (29002.m000150, 30068.m002599, 30170.m014182, and 29667.m000353). One conserved hypothetical protein (29667.m000353) showed high homology to an A. thaliana chaperone binding-ATPase activator (AT5G58110) (Fig. 9b).

In Arabidopsis, the oxidation-related zinc finger 2 (AtOZF2; AT4G29190) is involved in regulation of transcription and has sequence-specific DNA binding transcription factor activity. AtOZF2 is involved in ABA and salt stress responses through the ABI2-mediated signaling pathway (Huang et al., 2012). AtOZF2 is an AtOZF1 homolog, which confers oxidative stress tolerance to plants (Huang et al., 2011). It was demonstrated that AtOZF1 and AtOZF2 are important regulators for plant tolerance to abiotic stress (Huang et al., 2012). WD40 proteins play a crucial role in diverse protein-protein interactions by acting as scaffolding molecules and thus assisting in the proper activity of proteins (Mishra et al., 2014). Finally, MYB transcription factors are composed of one, two, or three imperfect helix-turn-helix repeats that recognize the major groove of DNA and which are involved in a variety of plant-specific processes, including cell morphogenesis, secondary metabolism, cell differentiation, and stress responses (Shin et al., 2011; Zhang et al., 2011). These genes constitute good candidates for further characterization of temperature-responsive molecular mechanisms in $R$. communis.

3.3. Additional evidence to support the hypothesis that during the initial phase of imbibition $R$. communis seeds perceive partial hydration as a drought stress and therefore accumulate gamma-aminobutyric acid (GABA)

We demonstrated that GABA levels were higher in $6 \mathrm{~h}$ imbibed seeds (6 hIS) samples imbibed at $20^{\circ} \mathrm{C}$ than at $35^{\circ} \mathrm{C}$ (Ribeiro et al., 2015c). Imbibing seeds possess very negative matrix potential because initially little or no water is left for uptake by the cells of the embryo. Seeds imbibed at $20^{\circ} \mathrm{C}$ have lower water content that seeds imbibed at $35^{\circ} \mathrm{C}$. Therefore, seeds imbibed at $20^{\circ} \mathrm{C}$ have a lower matrix potential than seeds imbibed at $35^{\circ} \mathrm{C}$ resulting in possible water stress. Based on our findings, we suggested that during early imbibition ( $6 \mathrm{hIS}$ ), R. communis seeds experience a drought stress-like condition as a result of partial hydration, resulting in the accumulation of GABA (Ribeiro et al., 


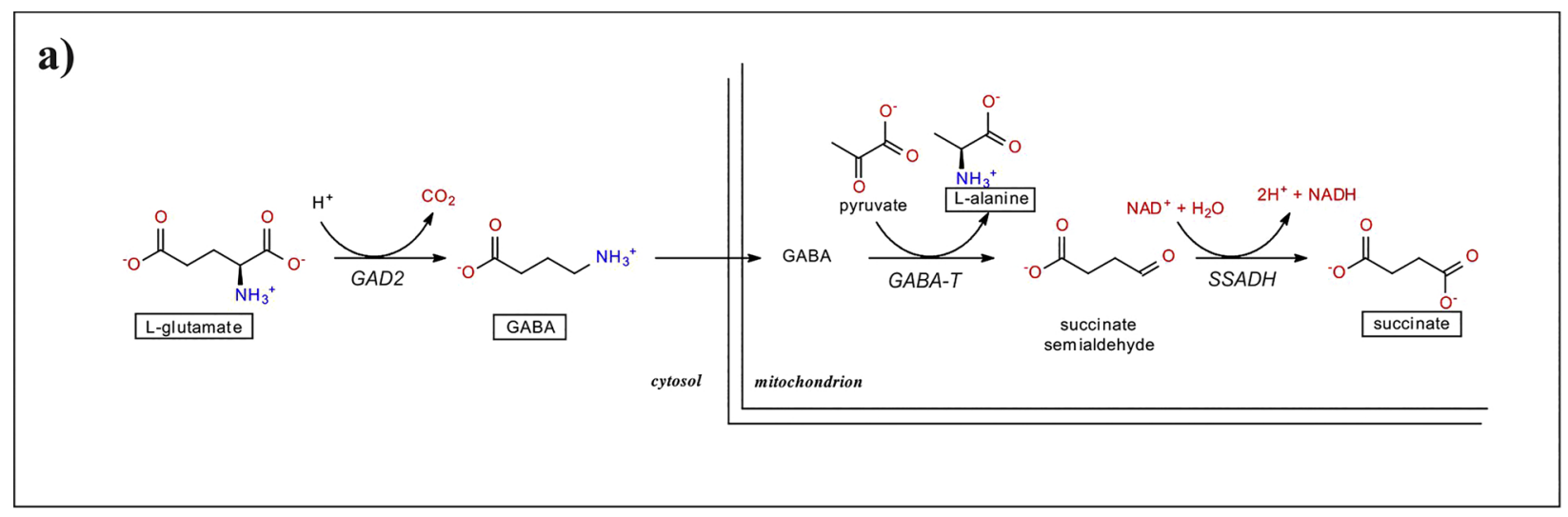

b)

GADI

27914.m000425

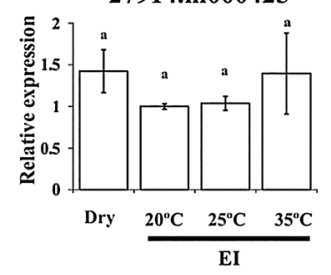

$G A B A-T$

30106.m000666

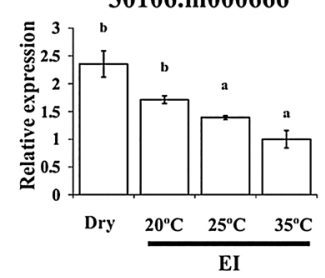

GAD2 27914.m000427

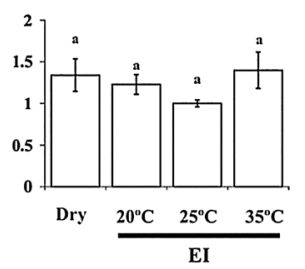

$S S A D H$

29678.m000496

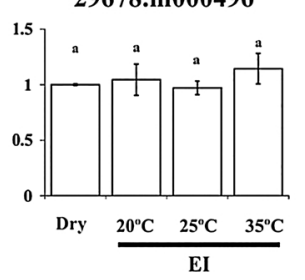

$G A D 3$

29662.m000447

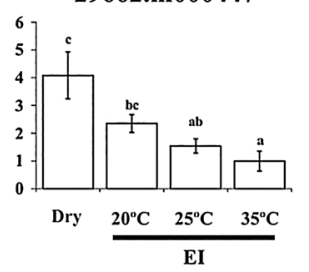

GAD4 29780.m001375

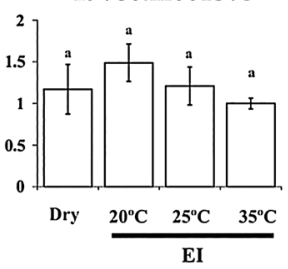

$G A D 5$

29780.m001376

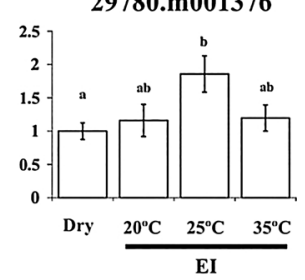

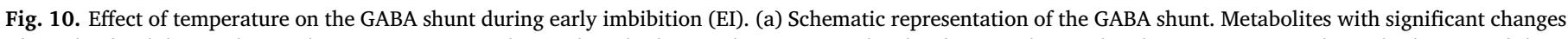

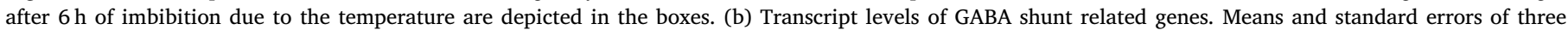

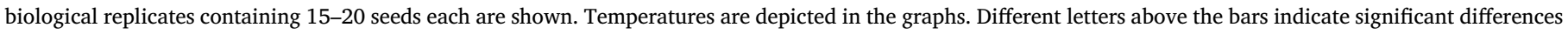
between samples by Tukey's HSD ( $\mathrm{p}<0.05$ ).

2015c). To provide additional support for this hypothesis, we mined our transcriptome data of EI samples searching for transcripts of genes involved in the GABA shunt. The first enzyme in the GABA shunt is glutamate decarboxylase (GAD) which catalyzes the conversion of glutamate to GABA and $\mathrm{CO}_{2}$ (Fig. 10a) (Rashmi et al., 2018; Renault et al., 2010). The $R$. communis genome contains five sequences putatively annotated as glutamate decarboxylase (RcGAD1, RcGAD2, RcGAD3, RcGAD4, and RcGAD5). Transcript levels of four glutamate decarboxylases (RcGAD1, RcGAD2, RcGAD4, and RcGAD5) showed none or little variation among EI samples. Transcript levels of RcGAD3 were 2.34 -fold greater in EI seeds imbibed at $20^{\circ} \mathrm{C}$ than at $35^{\circ} \mathrm{C}$ (Fig. 10b). This is, however, much lower than what was observed for 6 hIS in which transcript levels of RcGAD3 were 8.54-fold greater in seeds imbibed at $20^{\circ} \mathrm{C}$ than at $35^{\circ} \mathrm{C}$. Another important remark is that in $6 \mathrm{hIS}$ transcript levels of RcGAD2 were 7.68-fold greater in seeds imbibed at $20{ }^{\circ} \mathrm{C}$ than at $35^{\circ} \mathrm{C}$ (Ribeiro et al., 2015c). A similar reduction in the difference of the transcript levels of aminobutyrate transaminase (GABA-T) was also observed among EI samples. Transcript levels of GABA-T were 1.71-fold greater in EI seeds imbibed at $20^{\circ} \mathrm{C}$ than at $35^{\circ} \mathrm{C}$ (Fig. 10b), whereas in $6 \mathrm{hIS}$ transcript levels of $G A B A-T$ were 2.47 -fold greater in seeds imbibed at $20^{\circ} \mathrm{C}$ than at $35^{\circ} \mathrm{C}$ (Ribeiro et al., 2015c). Finally, transcript levels of succinic semialdehyde dehydrogenase $(S S A D H)$ showed no variation among EI samples, whereas in $6 \mathrm{hIS}$ transcript levels of $S S A D H$ were 1.95 -fold greater in seeds imbibed at $20^{\circ} \mathrm{C}$ than at $35^{\circ} \mathrm{C}$ (Fig. 10b). Taken together, these results support our initial hypothesis that during the initial phase of imbibition $R$. communis seeds perceive partial hydration as a drought stress and therefore accumulate GABA.

\section{Conclusion}

$R$. communis is able to grow in dry and hot environments where other crops would fail to grow and produce high yield. This species is, therefore, considered to be tolerant to a diverse range of environmental stresses. In order to uncover the molecular mechanisms that could explain the thermo-sensitive window identified during $R$. communis seed germination at high temperatures, we applied a genomics approach using microarray analysis to determine transcriptome changes during seed germination at 20,25 and $35{ }^{\circ} \mathrm{C}$. The majority of transcript modulation were associated to differences in developmental stage, followed by temperature and the interaction between stage and temperature. By using the concept that in the PCA analysis proximity means similarity, seeds imbibed at $20^{\circ} \mathrm{C}$ and $25^{\circ} \mathrm{C}$ show closer transcriptome, than seeds imbibed at $35^{\circ} \mathrm{C}$. Temperature had major effect on metabolic processes and it appears that high temperature compromises seedling development by down-regulating energy-generating metabolic processes which are crucial to support successful seedling establishment. Additionally, temperature had a large effect on transcriptional reprogramming. 
Finally, we provided further evidence to support the hypothesis that during the initial phase of imbibition $R$. communis seeds perceive partial hydration as a drought stress and therefore accumulate GABA. Furthermore, a large number of high-temperature responsive genes were identified during the seed germination process. Some genes might be involved in specific mechanism in response to heat stress and, therefore, deserve to pay more attention. These results allowed us to understand the molecular adaptation mechanism of $R$. communis thermo-sensitive window during $R$. communis seed germination at high temperatures, which will be very helpful in developing strategies for $R$. communis crop improvement research. This includes the improvement of important agronomic traits such as relative growth rate, seed yield, and oil content.

\section{Conflict of interest}

The authors declare no conflict of interest.

\section{Acknowledgments}

Financial support was provided by Universidade Federal da Bahia (UFBA; Project $n^{\circ}$ 11301, EDITAL PROPCI/PROPG 004/2016), Fundação de Apoio à Pesquisa do Estado da Bahia (FAPESB; Project $n^{\underline{0}}$ INT007/2014), Conselho Nacional de Desenvolvimento Científico e Tecnológico (CNPq; (Project $\mathrm{n}^{\circ}$ 200745/2011-5 and 400825/2014-7) and Coordenação de Aperfeiçoamento de Pessoal de Nível Superior (CAPES).

\section{Appendix A. Supplementary data}

Supplementary material related to this article can be found, in the online version, at doi:https://doi.org/10.1016/j.indcrop.2018.10.024.

\section{References}

Akter, N., Rafiqul Islam, M., 2017. Heat stress effects and management in wheat. A review. Agron. Sustain. Dev. 37.

Basnet, R.K., Moreno-Pachon, N., Lin, K., Bucher, J., Visser, R.G.F., Maliepaard, C., Bonnema, G., 2013. Genome-wide analysis of coordinated transcript abundance during seed development in different Brassica rapa morphotypes. BMC Genomics 14.

Berg, J.M., Tymoczko, J.L., Stryer, L., 2002. Section 20.1, the calvin cycle synthesizes hexoses from carbon dioxide and Water. In: Freeman, W.M. (Ed.), Biochemistry, ed. New York.

Bittencourt, M.L.F., Ribeiro, P.R., Franco, R.L.P., Hilhorst, H.W.M., de Castro, R.D., Fernandez, L.G., 2015. Metabolite profiling, antioxidant and antibacterial activities of Brazilian propolis: use of correlation and multivariate analyses to identify potential bioactive compounds. Food Res. Int. 76, 449-457.

Borroto, K., Dure Iii, L., 1987. The globulin seed storage proteins of flowering plants are derived from two ancestral genes. Plant. Mol. Biol. 8, 113-131.

Cesar, Ad.S., Batalha, M.O., 2010. Biodiesel production from castor oil in Brazil: a difficult reality. Energy Policy 38, 4031-4039.

Chamorro, D., Luna, B., Moreno, J.M., 2017. Germination responses to current and future temperatures of four seeder shrubs across a latitudinal gradient in western Iberia. Am. J. Bot. 104, 83-91.

Chan, A.P., Crabtree, J., Zhao, Q., Lorenzi, H., Orvis, J., Puiu, D., Melake-Berhan, A, Jones, K.M., Redman, J., Chen, G., Cahoon, E.B., Gedil, M., Stanke, M., Haas, B.J., Wortman, J.R., Fraser-Liggett, C.M., Ravel, J., Rabinowicz, P.D., 2010. Draft genome sequence of the oilseed species Ricinus communis. Nat. Biotechnol. 28, 951-956.

Chauhan, H., Khurana, N., Nijhavan, A., Khurana, J.P., Khurana, P., 2012. The wheat chloroplastic small heat shock protein (sHSP26) is involved in seed maturation and germination and imparts tolerance to heat stress. Plant Cell Environ. 35, 1912-1931.

Chileh, T., Esteban-García, B., Alonso, D.L., García-Maroto, F., 2010. Characterization of the 11 s globulin gene family in the castor plant Ricinus communis L. J. Agric. Food. Chem. 58, 272-281.

Chiu, R.S., Nahal, H., Provart, N.J., Gazzarrini, S., 2012. The role of the Arabidopsis FUSCA3 transcription factor during inhibition of seed germination at high temperature. BMC Plant Biol. 12.

Cochrane, A., 2017. Modelling seed germination response to temperature in Eucalyptus L'Her. (Myrtaceae) species in the context of global warming. Seed Sci. Res. 27, 99-109.

Fahad, S., Bajwa, A.A., Nazir, U., Anjum, S.A., Farooq, A., Zohaib, A., Sadia, S., Nasim, W., Adkins, S., Saud, S., Ihsan, M.Z., Alharby, H., Wu, C., Wang, D., Huang, J., 2017. Crop production under drought and heat stress: plant responses and management options. Front. Plant Sci. 8.

Fukasawa, T., Hara-nishimura, I., Nishimura, M., 1988. Biosynthesis, intracellular transport and in vitro processing of 11S globulin precursor proteins of developing castor bean endosperm. Plant Cell Physiol. 29, 339-345.

Goggin, D.E., Steadman, K.J., Emery, R.J.N., Farrow, S.C., Benech-Arnold, R.L., Powles, S.B., 2009. ABA inhibits germination but not dormancy release in mature imbibed seeds of Lolium rigidum Gaud. J. Exp. Bot. 60, 3387-3396.

Gomes, M.M.A., 2011. Physiological effects related to brassinosteroid application in plants. Brassinosteroids: A Class of Plant Hormone. Springer, Netherlands, pp. 193-242.

Gomes Neto, V., Ribeiro, P.R., Del-Bem, L.E., Bernal, D.T., Cunha Lima, S.T., Ligterink, W., Fernandez, L.G., de Castro, R.D., 2018. Characterization of the superoxide dismutase gene family in seeds of two Ricinus communis L. Genotypes submitted to germination under water restriction conditions. Environ. Exp. Bot. 155, 453-463.

Graham, I.A., 2008. Seed storage oil mobilization. Annu. Rev. Plant Biol. 59, 115-142.

Harris, K.L., Thomson, R.E.S., Strohmaier, S.J., Gumulya, Y., Gillam, E.M.J., 2018 Determinants of thermostability in the cytochrome P450 fold. Biochimica et Biophysica Acta - Proteins Proteom. 1866, 97-115.

Hasanuzzaman, M., Nahar, K., Alam, M.M., Roychowdhury, R., Fujita, M., 2013. Physiological, biochemical, and molecular mechanisms of heat stress tolerance in plants. Int. J. Mol. Sci. 14, 9643-9684.

Hausjell, J., Halbwirth, H., Spadiut, O., 2018. Recombinant production of eukaryotic cytochrome P450s in microbial cell factories. Biosci. Rep. 38.

Horgen, P.A., Key, J.L., 1973. The DNA-directed RNA polymerases of soybean. BBA Sect. Nucleic Acids Protein Synth. 294, 227-235.

Hou, S., Niu, H., Tao, Q., Wang, S., Gong, Z., Li, S., Weng, Y., Li, Z., 2017. A mutant in the CsDET2 gene leads to a systemic brassinosteriod deficiency and super compact phenotype in cucumber (Cucumis sativus L.). Theor. Appl. Genet. 130, 1693-1703.

Huang, P., Chung, M.S., Ju, H.W., Na, H.S., Lee, D.J., Cheong, H.S., Kim, C.S., 2011. Physiological characterization of the Arabidopsis thaliana oxidation-related zinc finger 1, a plasma membrane protein involved in oxidative stress. J. Plant Res. 124 699-705.

Huang, P., Ju, H.W., Min, J.H., Zhang, X., Chung, J.S., Cheong, H.S., Kim, C.S., 2012. Molecular and physiological characterization of the arabidopsis thaliana oxidationrelated zinc finger 2, a plasma membrane protein involved in ABA and salt stress response through the ABI2-mediated signaling pathway. Plant Cell Physiol. 53, 193-203.

Jiang, W.B., Huang, H.Y., Hu, Y.W., Zhu, S.W., Wang, Z.Y., Lin, W.H., 2013. Brassinosteroid regulates seed size and shape in Arabidopsis. Plant Physiol. 162, 1965-1977.

Jiménez-López, S., Mancera-Martínez, E., Donayre-Torres, A., Rangel, C., Uribe, L., March, S., Jiménez-Sánchez, G., Sánchez De Jiménez, E., 2011. Expression profile of maize (Zea mays L.) embryonic axes during germination: translational regulation of ribosomal protein mRNAs. Plant Cell Physiol. 52, 1719-1733.

Kotak, S., Larkindale, J., Lee, U., von Koskull-Döring, P., Vierling, E., Scharf, K.D., 2007. Complexity of the heat stress response in plants. Curr. Opin. Plant Biol. 10, 310-316.

Kumar, P., Kesari, P., Dhindwal, S., Choudhary, A.K., Katiki, M., Neetu, Verma,A., Ambatipudi, K., Tomar, S., Sharma, A.K., Mishra, G., Kumar, P., 2017. A novel function for globulin in sequestering plant hormone: crystal structure of Wrightia tinctoria 11S globulin in complex with auxin. Sci. Rep. 7, 4705.

Kushiro, T., Okamoto, M., Nakabayashi, K., Yamagishi, K., Kitamura, S., Asami, T., Hirai, N., Koshiba, T., Kamiya, Y., Nambara, E., 2004. The Arabidopsis cytochrome P450CYP707A encodes ABA 8' -hydroxylases: key enzymes in ABA catabolism. EMBO J. 23, 1647-1656.

Lee, G.J., Vierling, E., 2000. A small heat shock protein cooperates with heat shock protein 70 systems to reactivate a heat-denatured protein. Plant Physiol. 122, 189-197.

Li, C., Li, M., Dunwell, J.M., Zhang, Y.M., 2012. Gene duplication and an accelerated evolutionary rate in $11 \mathrm{~S}$ globulin genes are associated with higher protein synthesis in dicots as compared to monocots. BMC Evol. Biol. 12.

Li, Y.F., Wang, Y., Tang, Y., Kakani, V.G., Mahalingam, R., 2013. Transcriptome analysis of heat stress response in switchgrass (Panicum virgatum L.). BMC Plant Biol. 13.

Liao, J.L., Zhou, H.W., Peng, Q., Zhong, P.A., Zhang, H.Y., He, C., Huang, Y.J., 2015. Transcriptome changes In rice (oryza sativa L.) In response to high night temperature stress at the early milky stage. BMC Genomics 16.

Lv, B., Tian, H., Zhang, F., Liu, J., Lu, S., Bai, M., Li, C., Ding, Z., 2018. Brassinosteroids regulate root growth by controlling reactive oxygen species homeostasis and dual effect on ethylene synthesis in Arabidopsis. PLos Genet. 14.

Mangrauthia, S.K., Agarwal, S., Sailaja, B., Sarla, N., Voleti, S.R., 2016. Transcriptome analysis of Oryza sativa (rice) seed germination at high temperature shows dynamics of genome expression associated with hormones signalling and abiotic stress pathways. Trop. Plant Biol. 9, 215-228.

Mishra, A.K., Muthamilarasan, M., Khan, Y., Parida, S.K., Prasad, M., 2014. Genome-wide investigation and expression analyses of WD40 protein family in the model plant foxtail millet (Setaria italica L.). PLoS One 9.

Naydenov, N.G., Khanam, S., Siniauskaya, M., Nakamura, C., 2010. Profiling of mitochondrial transcriptome in germinating wheat embryos and seedlings subjected to cold, salinity and osmotic stresses. Genes Genet. Syst. 85, 31-42.

Peal, L., Jambunathan, N., Mahalingam, R., 2011. Phylogenetic and expression analysis of RNA-binding proteins with triple RNA recognition motifs in plants. Mol. Cells 31, $55-64$.

Qu, A.L., Ding, Y.F., Jiang, Q., Zhu, C., 2013. Molecular mechanisms of the plant heat stress response. Biochem. Biophys. Res. Commun. 432, 203-207.

Que, F., Wang, G.L., Xu, Z.S., Wang, F., Xiong, A.S., 2017. Transcriptional regulation of brassinosteroid accumulation during carrot development and the potential role of brassinosteroids in petiole elongation. Front. Plant Sci. 8.

Rachmilevitch, S., Xu, Y., Gonzalez-Meler, M.A., Huang, B., Lambers, H., 2007. Cytochrome and alternative pathway activity in roots of thermal and non-thermal 
agrostis species in response to high soil temperature. Physiol. Plant. 129, 163-174. Raines, C.A., 2003. The calvin cycle revisited. Photosynth. Res. 75, 1-10.

Rashmi, D., Zanan, R., John, S., Khandagale, K., Nadaf, A., 2018. $\gamma$-aminobutyric acid (GABA): biosynthesis, role, commercial production, and applications. Stud. Nat. Prod. Chem. 413-452.

Renault, H., Roussel, V., El Amrani, A., Arzel, M., Renault, D., Bouchereau, A., Deleu, C., 2010. The Arabidopsis pop2-1 mutant reveals the involvement of GABA transaminase in salt stress tolerance. BMC Plant Biol. 10, 20.

Ribeiro, P.R., Fernandez, L.G., de Castro, R.D., Ligterink, W., Hilhorst, H.W.M., 2014. Physiological and biochemical responses of Ricinus communis seedlings to different temperatures: a metabolomics approach. BMC Plant Biol. 14.

Ribeiro, P.R., Ligterink, W., Hilhorst, H.W.M., 2015a. Expression profiles of genes related to carbohydrate metabolism provide new insights into carbohydrate accumulation in seeds and seedlings of Ricinus communis in response to temperature. Plant Physiol. Biochem. 95, 103-112.

Ribeiro, P.R., Willems, L.A.J., Mudde, E., Fernandez, L.G., de Castro, R.D., Ligterink, W., Hilhorst, H.W.M., 2015b. Metabolite profiling of the oilseed crop Ricinus communis during early seed imbibition reveals a specific metabolic signature in response to temperature. Ind. Crop Prod. 67, 305-309.

Ribeiro, P.R., Willems, L.A.J., Mutimawurugo, M.C., Fernandez, L.G., de Castro, R.D., Ligterink, W., Hilhorst, H.W.M., 2015c. Metabolite profiling of Ricinus communis germination at different temperatures provides new insights into thermo-mediated requirements for successful seedling establishment. Plant Sci. 239, 180-191.

Ribeiro, P.R., Zanotti, R.F., Deflers, C., Fernandez, L.G., de Castro, R.D., Ligterink, W., Hilhorst, H.W.M., 2015d. Effect of temperature on biomass allocation in seedlings of two contrasting genotypes of the oilseed crop Ricinus communis. J. Plant Physiol. 185, 31-39.

Sandhu, K.S., Hagely, K., Neff, M.M., 2012. Genetic interactions between brassinosteroidinactivating P450s and photomorphogenic photoreceptors in Arabidopsis thaliana. G3 (Bethesda, Md.) 2, 1585-1593.

Santos, P.M., Batista, D.L.J., Ribeiro, L.A.F., Boffo, E.F., de Cerqueira, M.D., Martins, D., de Castro, R.D., de Souza-Neta, L.C., Pinto, E., Zambotti-Villela, L., Colepicolo, P., Fernandez, L.G., Canuto, G.A.B., Ribeiro, P.R., 2018. Identification of antioxidant and antimicrobial compounds from the oilseed crop Ricinus communis using a multiplatform metabolite profiling approach. Ind. Crop. Prod. 124, 834-844.

Shin, D., Moon, S.J., Han, S., Kim, B.G., Park, S.R., Lee, S.K., Yoon, H.J., Lee, H.E., Kwon, H.B., Baek, D., Yi, B.Y., Byun, M.O., 2011. Expression of StMYB1R-1, a novel potato single MYB-like domain transcription factor, increases drought tolerance. Plant Physiol. 155, 421-432.

Smith, A.M., Zeeman, S.C., Smith, S.M., 2005. Starch degradation. Annu. Rev. Plant Biol. 73-96.

Snoek, L.B., Sterken, M.G., Volkers, R.J.M., Klatter, M., Bosman, K.J., Bevers, R.P.J.,
Riksen, J.A.G., Smant, G., Cossins, A.R., Kammenga, J.E., 2014. A rapid and massive gene expression shift marking adolescent transition in C. Elegans. Sci. Rep. 4.

Soares-Cavalcanti, N.M., Belarmino, L.C., Kido, E.A., Pandolfi, V., Marcelino-Guimarães, F.C., Rodrigues, F.A., Pereira, G.A.G., Benko-Iseppon, A.M., 2012. Overall picture of expressed heat shock factors in Glycine max, lotus japonicusand medicago truncatula. Genet. Mol. Biol. 35, 247-259.

Steber, C.M., McCourt, P., 2001. A role for brassinosteroids in germination in Arabidopsis Plant Physiol. 125, 763-769.

Sun, W., Van Montagu, M., Verbruggen, N., 2002. Small heat shock proteins and stress tolerance in plants. Biochimica et Biophysica Acta - Gene Struct. Express. 1577, 1-9.

Unterholzner, S.J., Rozhon, W., Papacek, M., Ciomas, J., Lange, T., Kugler, K.G., Mayer, K.F., Sieberer, T., Poppenberger, B., 2015. Brassinosteroids are master regulators of gibberellin biosynthesis in Arabidopsis. Plant Cell 27, 2261-2272.

Wan, C.Y., Wilkins, T.A., 1994. A modified hot borate method significantly enhances the yield of high-quality RNA from cotton (Gossypium hirsutum L.). Anal. Biochem. 223, 7-12.

Wang, Z.Y., Zhu, J.Y., Sae-Seaw, J., 2013. Brassinosteroid signaling. Development (Cambridge) 140, 1615-1620.

Wang, D.L., Du, P.Y., Huan, L., Xiao, W., Chen, X.D., Li, L., Gao, D.S., 2016. Molecular cloning and expression analysis of CYP707A gene family in peach. Zhiwu Shengli Xuebao/Plant Physiolo. J. 52, 659-668.

Wei, Y., Ang, E.L., Zhao, H., 2018. Recent developments in the application of P450 based biocatalysts. Curr. Opin. Chem. Biol. 43, 1-7.

Wolfe, M.D., Tonsor, S.J., 2014. Adaptation to spring heat and drought in northeastern Spanish Arabidopsis thaliana. New Phytol. 201, 323-334.

Xia, J., Mandal, R., Sinelnikov, I.V., Broadhurst, D., Wishart, D.S., 2012. MetaboAnalyst 2.0-a comprehensive server for metabolomic data analysis. Nucleic Acids Res. 40, W127-W133.

Yan, J., Yu, L., Xuan, J., Lu, Y., Lu, S., Zhu, W., 2016. De novo transcriptome sequencing and gene expression profiling of spinach (Spinacia oleracea L.) leaves under heat stress. Sci. Rep. 6.

Zahurak, M., Parmigiani, G., Yu, W., Scharpf, R.B., Berman, D., Schaeffer, E., Shabbeer, S., Cope, L., 2007. Pre-processing Agilent microarray data. BMC Bioinf. 8.

Zhang, X., Ju, H.W., Chung, M.S., Huang, P., Ahn, S.J., Kim, C.S., 2011. The R-R-type MYB-like transcription factor, AtMYBL, is involved in promoting leaf senescence and modulates an abiotic stress response in arabidopsis. Plant Cell Physiol. 52, 138-148.

Zheng, G., Tian, B., Zhang, F., Tao, F., Li, W., 2011. Plant adaptation to frequent alterations between high and low temperatures: remodelling of membrane lipids and maintenance of unsaturation levels. Plant Cell Environ. 34, 1431-1442.

Zhenzhen, G., Gongxun, X., Dongling, W., Li, L., Xiude, C., Ling, L., Xiling, F., Dongsheng, G., 2018. Functional analysis of peach PpeCYP707As gene in Arabidopsis thaliana overexpressing plants. Acta Horticult. Sin. 45, 239-249. 